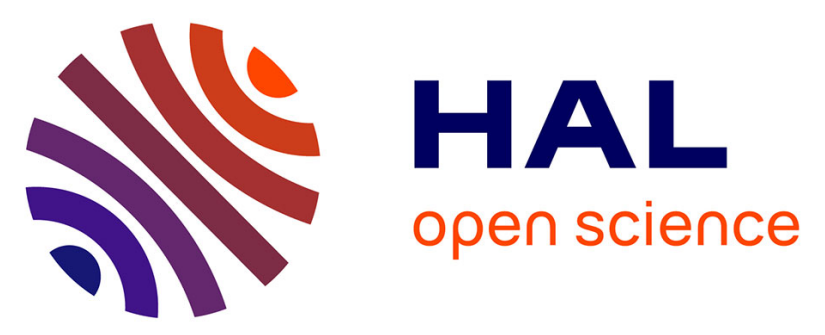

\title{
Rheological Properties of Covalent Adaptable Networks with 1,2,3-Triazolium Cross-Links: The Missing Link between Vitrimers and Dissociative Networks
}

Antoine Jourdain, Rawnaq Asbai, Omaima Anaya, Mohamed Chehimi, Eric

Drockenmuller, Damien Montarnal

\section{To cite this version:}

Antoine Jourdain, Rawnaq Asbai, Omaima Anaya, Mohamed Chehimi, Eric Drockenmuller, et al.. Rheological Properties of Covalent Adaptable Networks with 1,2,3-Triazolium Cross-Links: The Missing Link between Vitrimers and Dissociative Networks. Macromolecules, 2020, 53 (6), pp.1884-1900. 10.1021/acs.macromol.9b02204 . hal-02927084

\section{HAL Id: hal-02927084 \\ https://hal.science/hal-02927084}

Submitted on 12 Nov 2020

HAL is a multi-disciplinary open access archive for the deposit and dissemination of scientific research documents, whether they are published or not. The documents may come from teaching and research institutions in France or abroad, or from public or private research centers.
L'archive ouverte pluridisciplinaire HAL, est destinée au dépôt et à la diffusion de documents scientifiques de niveau recherche, publiés ou non, émanant des établissements d'enseignement et de recherche français ou étrangers, des laboratoires publics ou privés. 


\title{
Rheological Properties of Covalent Adaptable Networks with 1,2,3- Triazolium Cross-Links: The Missing Link between Vitrimers and Dissociative Networks
}

\author{
Antoine Jourdain, Rawnaq Asbai, Omaima Anaya, Mohamed M. Chehimi, Eric Drockenmuller,* \\ and Damien Montarnal*
}

Cite This: Macromolecules 2020, 53, 1884-1900

Read Online

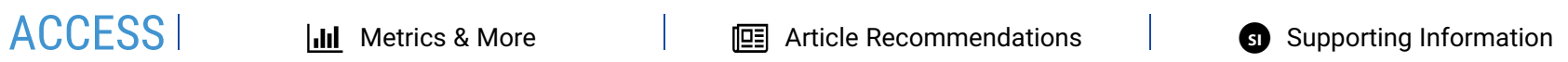

ABSTRACT: Vitrimers, in stringent contrast to dissociative networks, involve associative covalent exchanges and remain fully cross-linked at all temperatures. However, we have previously reported on poly(1,2,3-triazolium) dynamic networks that exhibit linear rheological characterization indistinguishable from vitrimers although being based on a dissociative covalent exchange process, i.e., de- $N$-alkylation and re- $N$-alkylation reactions. Herein, we highlight the main features of dissociative and associative covalent adaptable networks (CANs) and discuss their respective linear rheological behaviors. After giving a detailed overview of the extent and potential of dynamic polymer networks having 1,2,3-triazolium cross-links in particular and CANs involving trans- $\mathrm{N}$-alkylation

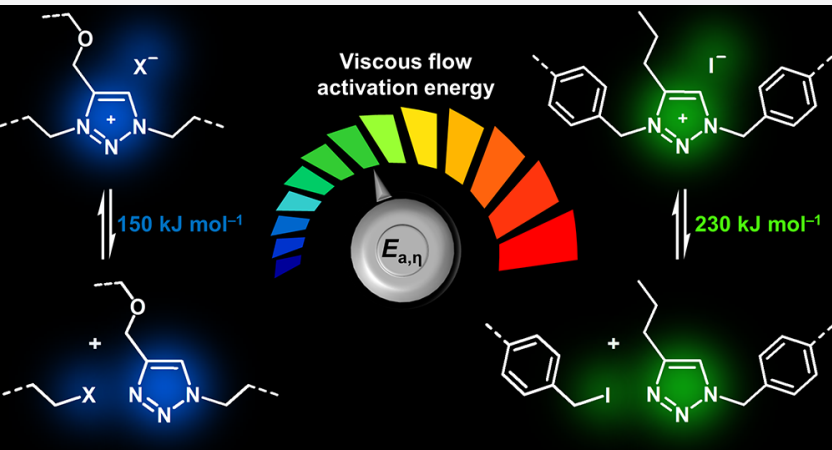
exchanges in general, we perform a detailed rheological

comparative characterization of previously described aliphatic 1,2,3-triazolium-based dynamic networks and a new bicomponent thermosetting system issued from the mixing of linear polystyrene chains having complementary benzyl iodide and 1,2,3-triazole pendent groups. We propose a simple but comprehensive rheological characterization methodology that enables proper comparison between all types of CANs, i.e., vitrimers and dissociative networks. Owing to the combination of a high glass transition temperature dynamic network and fast trans- $N$-alkylation exchanges in this new dissociative network, it is possible to characterize both glass transition and network relaxation with single rheological experiments. We provide clear experimental evidence that although located within a narrow temperature range, the temperature dependences of these two transitions are distinct and follow WLF and Arrhenius models, respectively.

\section{INTRODUCTION}

Covalent adaptable networks (CANs) involving dynamic covalent cross-links ${ }^{1-7}$ have gained a growing interest in the context of advanced polymer materials with enhanced thermomechanical and solvent-resistance properties. In contrast to conventional thermosets, the relaxation dynamics of CANs can be adjusted through temperature changes or UV-irradiation to confer creep and stress-cracking resistance in conditions of slow dynamics or malleability and plasticity in conditions of fast dynamics.

In many CANs in which relaxations associated with the bond exchange mechanism are slower and sufficiently distinct from the glass transition, the relaxation time spectrum of these materials $H(\tau, T)$ can be characterized by two clear thermomechanical transitions, that is, the glass-to-rubber relaxation with spectrum $H_{\mathrm{Glass}}(\tau, T)$ involving cooperative motion at the segmental scale $(1-3 \mathrm{~nm})^{8}$ and the rubber-to-liquid relaxation with spectrum $H_{\text {Network }}(\tau, T)$ shifted to longer time scales involving cross-link exchanges with mobility at the scale of the mesh of the network. The zero-shear viscosity $\eta_{0}(T)$ of CANs that determines their flow capacity is thus essentially driven by covalent exchanges of the cross-links: $\eta_{0}(T)=\int_{-\infty}^{\infty} \tau\left(H_{\mathrm{Glass}}(\ln \right.$ $\left.\tau, T)+H_{\text {Network }}(\ln \tau, T)\right) \mathrm{d}(\ln \tau) \approx \int_{-\infty}^{\infty} \tau H_{\text {Network }}(\ln \tau, T) \mathrm{d}(\ln \tau)$. Remarkably, it has been shown that most dynamic networks display a network relaxation with a narrow distribution of relaxation times $\left(H_{\text {Network }}(\tau, T) \approx 0\right.$ for $\left.\tau \neq \tau^{*}(T)\right)$, which enables to express the zero-shear viscosity in mainly two contributions, the main relaxation time $\tau^{*}(T)$ and the plateau modulus $G_{0}(T)$ related to the cross-link density: $\eta_{0}(T) \approx$ $\tau^{*}(T) \int_{-\infty}^{\infty} H_{\text {Network }}(\ln \tau, T) \mathrm{d}(\ln \tau) \approx \tau^{*}(T) G_{0}(T)$.

A distinction is often made between vitrimers, ${ }^{9-12}$ that is, a specific example of CANs featuring a constant cross-link density

Received: October 17, 2019

Revised: February 20, 2020

Published: March 9, 2020 
upon temperature changes and in which terminal mechanical relaxation (i.e., flow) is controlled by an associative bond exchange mechanism (Figure 1a) and dissociative networks in which an increase in temperature induces both the decrease of cross-link density and a shorter bond lifetime (Figure 1b). ${ }^{13-16}$

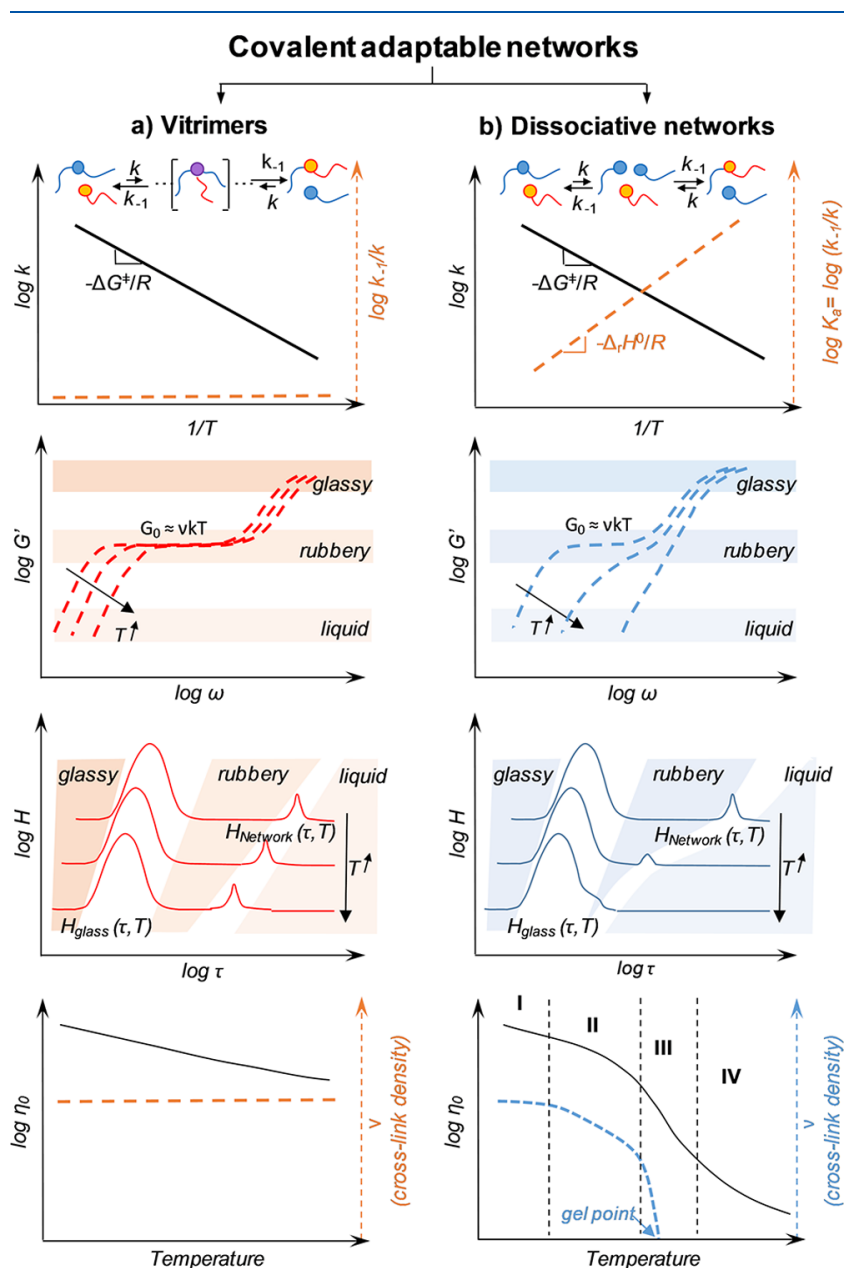

Figure 1. Comparison of the different physicochemical characteristics of (a) vitrimers and (b) dissociative networks. From top to bottom: (1) overall exchange mechanisms at stake in the network relaxation and corresponding thermodynamic parameters ( $k$ being the apparent rate of exchange and $K_{\mathrm{a}}=k_{-1} / k$ the apparent association equilibrium constant), (2) typical evolutions of storage moduli $G^{\prime}(\omega, T)$ with frequency, (3) typical relaxation time spectra $H(\tau, T)$, and (4) evolutions of zero-shear viscosity $\eta_{0}(T)$ and cross-link density at temperatures above the glass transition.

In vitrimers, as $G_{0}$ varies only weakly with temperature up to the degradation temperature (entropic elasticity), the temperature dependence of the zero-shear viscosity should thus be solely controlled by the kinetics of the bond exchange reaction. As a consequence, the reprocessability of vitrimers in the literature is up to now merely assessed from the temperature dependence of relaxation times, estimated from normalized stress relaxation data $G(t) / G_{0}=f\left(t / \tau^{*}\right)$ through various models (monoexponential, stretched exponential, and delayed exponential). All relaxation times obtained in this way follow an Arrhenius dependence $\tau^{*}(T) \sim \mathrm{e}^{E_{a}, \tau} / R T, E_{\mathrm{a}, \tau}$ being most of the time simply termed the activation energy. For the purpose of clearly defining the different parameters at stake, we will use here the term kinetic activation energy throughout this Perspective.
Creep measurements are more rarely encountered in the literature, yet they directly lead to zero-shear viscosities and enable to calculate the viscous flow activation energies $\eta^{*}(T) \sim$ $\mathrm{e}^{E_{a, n} / R T}$. As expected from networks maintaining a constant crosslink density, very comparable values for viscous flow activation energies and kinetic activation energies have been found for vitrimer materials, for example, $E_{\mathrm{a}, \tau}=80 \mathrm{~kJ} \mathrm{~mol}^{-1}$ and $E_{\mathrm{a}, \eta}=88 \mathrm{~kJ}$ $\mathrm{mol}^{-1}$ for the first vitrimer system reported based on epoxy-acid networks with the transesterification reaction catalyzed by $\mathrm{Zn}$ (II) species. ${ }^{9}$ It is also important to emphasize that great caution must be taken when relating these kinetic and viscous flow activation energies measured in networks to thermodynamic parameters of the corresponding exchange reactions and notably the Gibbs (barrier) activation energy $\Delta G^{\ddagger}$. In particular, the presence of catalysts, which are acknowledged for reducing the Gibbs activation energies of elementary (single step) reactions, can have very diverse effects on the overall activation energy. ${ }^{17}$ This discrepancy may be explained solely from enthalpic considerations by the fact that exchange reactions can occur through complex, multistep pathways (and all the more so when catalysis is involved) and that the calculation of the apparent Gibbs activation energy requires complete knowledge of all mechanistic steps. It is also likely that more complex entropic considerations involving the complete configurational space of the exchange reaction may even play a more important role. ${ }^{18}$ Notably, it has been shown recently by Du Prez, Winne, and co-workers that the kinetic activation energy of reversible activated thiol-yne addition can display significant differences when comparing exchange reactions in model molecules or when they are part of a highly cross-linked network. ${ }^{19}$ In most cases, while the relaxation times of vitrimers can be largely tuned by changing the stoichiometry or concentration of exchangeable reactants, ${ }^{20}$ the concentration of catalysts, ${ }^{9,21}$ or by phase segregation of the exchangeable units, $^{22,23}$ the $E_{\mathrm{a}, \tau}$ of vitrimers is characteristic of a given exchange reaction (including the nature of catalyst when applicable) and generally ranges from 50 to $150 \mathrm{~kJ} \mathrm{~mol}^{-1}$. It is also interesting to note that in a few cases when several mechanisms may coexist for the same exchange reaction multiple activation energies may be distinguished. ${ }^{24,25}$ Most vitrimer systems developed so far rely on covalent exchange reactions including concerted nucleophilic exchanges such as classical transesterifications involving vicinal alcohols $\left(E_{\mathrm{a}, \tau} \sim\right.$ 89-163 kJ mol ${ }^{-1}, 9,21,26-31$ although much higher $E_{\mathrm{a}, \tau}$ up to 250 $\mathrm{kJ} \mathrm{mol}^{-1}$ have been reported at very high temperatures for poly(butylene terephthalate) (PBT) vitrimers containing deprotectable diols). ${ }^{32}$ In addition, transcarbamoylation of urethanes, either involving vicinal alcohols $\left(E_{\mathrm{a}, \tau} \sim 99-159 \mathrm{~kJ}\right.$ $\mathrm{mol}^{-1}$ ) or in the absence of alcohols, most probably involving partial reversibility at higher temperatures $\left(E_{\mathrm{a}, \tau} \sim 114-184 \mathrm{~kJ}\right.$ $\left.\mathrm{mol}^{-1}\right),{ }^{33-37}$ transcarbonation $\left(E_{\mathrm{a}, \tau} \sim 80-120 \mathrm{~kJ} \mathrm{~mol}^{-1}\right){ }^{38}$ transamination of vinylogous urethanes $\left(E_{\mathrm{a}, \tau} \sim 31-129 \mathrm{~kJ}\right.$ $\left.\mathrm{mol}^{-1}\right),{ }^{17,24,39}$ transamination of imines $\left(E_{\mathrm{a}, \tau} \sim 49-81 \mathrm{~kJ}\right.$ $\left.\mathrm{mol}^{-1}\right),{ }^{40-42}$ transalkylation of sulfonium salts $\left(E_{\mathrm{a}, \tau} \sim 113-115\right.$

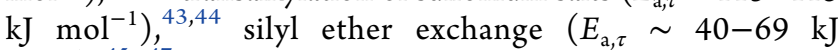
$\left.\mathrm{mol}^{-1}\right){ }^{45-47}$ oxime-promoted transesterification $\left(E_{\mathrm{a}, \tau} \sim 64 \mathrm{~kJ}\right.$ $\left.\mathrm{mol}^{-1}\right),{ }^{48}$ transthioetherification of Meldrum's acids $\left(E_{\mathrm{a}, \tau} \sim 63-\right.$ $\left.65 \mathrm{~kJ} \mathrm{~mol}^{-1}\right),{ }^{49}$ aminal transamination $\left(E_{\mathrm{a}, \tau} \sim 52-80 \mathrm{~kJ}\right.$ $\left.\mathrm{mol}^{-1}\right),{ }^{50}$ or transamination of diketoenamines $\left(E_{\mathrm{a}, \tau} \sim 49-60 \mathrm{~kJ}\right.$ $\left.\mathrm{mol}^{-1}\right),{ }^{51}$ paved the way toward tuning the functionality and properties of vitrimer materials by using chemical and structural design. Other miscellaneous vitrimer systems rely on alternative exchange mechanisms such as radical disulfide exchange $\left(E_{\mathrm{a}, \tau} \sim\right.$ 
Scheme 1. Main Covalent Exchange Reactions That Enable Malleability in CANs

\section{DISSOCIATIVE}

Furan-maleimide Diels Alder<smiles></smiles>

Transcarbamoylation of urethanes<smiles>[R]O[N+](=O)O[R]</smiles>

Amine urea exchange

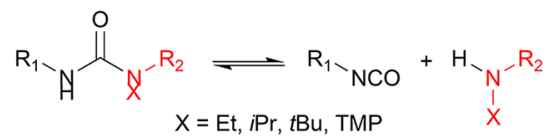

TAD-indole Alder-Ene<smiles>[R2]N1C(=O)NNN1C1([R])C=Nc2ccccc21</smiles><smiles>[R7]C1=C[NH2+]c2ccccc21</smiles>

Aminal transamination

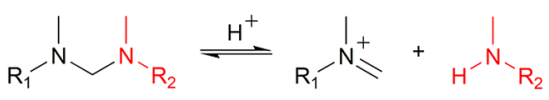

Oxime-promoted transcarbamoylation

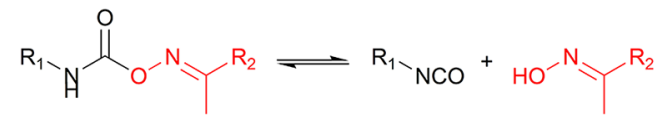

Imine transamination

$$
\underset{x}{=}=\mathrm{N}-\mathrm{R}_{2} \stackrel{\mathrm{H}_{3} \mathrm{O}^{+}}{\rightleftharpoons} \underset{x}{\mathrm{R}_{1}}=\mathrm{O}+\mathrm{H}_{2} \mathrm{~N}-\mathrm{R}_{2}
$$

Thioacetal exchange

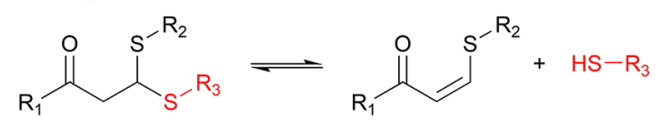

Trans- $N$-alkylation of 1,2,3-triazolium salts

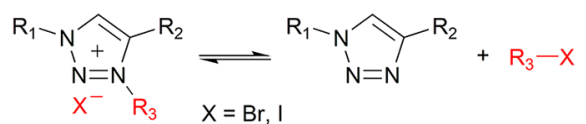

Trans- $N$-alkylation of pyridinium salts

$$
\mathrm{R}_{1}-\mathrm{R}_{\mathrm{Br}}^{\mathrm{N}-\mathrm{R}_{2}} \rightleftharpoons \mathrm{N}^{-}+\mathrm{Br}-\mathrm{R}_{2}
$$

Trans- $\mathrm{N}$-alkylation of anilinium salts<smiles></smiles>

\section{ASSOCIATIVE and MISCELLANEOUS}

Transesterification

$$
\overbrace{\mathrm{O}_{2}}^{\mathrm{R}_{1}}+\mathrm{R}_{3}-\mathrm{OH} \stackrel{\text { Catalyst }}{=} \overbrace{\substack{\mathrm{R}_{3} \\ \mathrm{R}_{2}}}^{\mathrm{R}_{1}}+\mathrm{R}_{2}-\mathrm{OH}
$$

Transamination of vinylogous urethanes

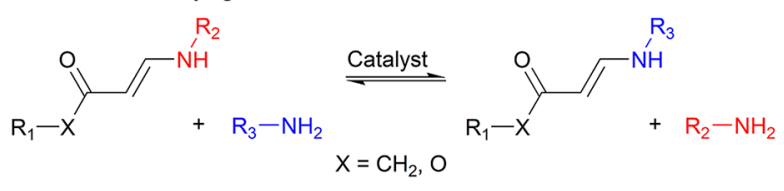

Transthioetherification of Meldrum's acids

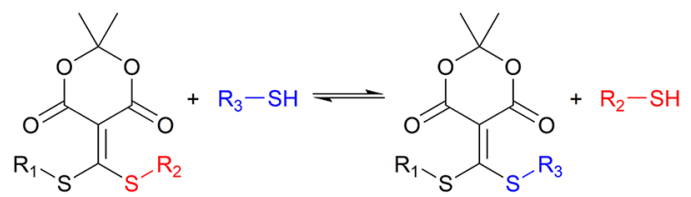

Transamination of diketoenamines<smiles>[R17]CC(N[R2])=C1C(=O)CC(C)(C)CC1=O</smiles>

Olefin metathesis<smiles>[R]C=[R17][CH+]C=C[R]</smiles>

Boronic ester exchange<smiles>[R]B1OCC([R])O1</smiles>

Silyl ether exchange

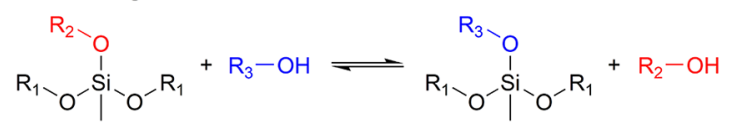

Transesterification of oxime esters

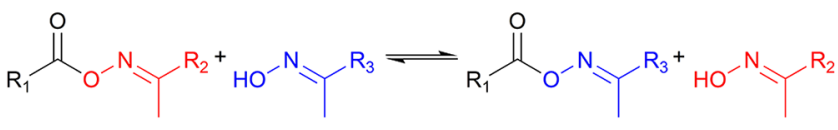

Transcarbonation

$$
\mathrm{R}_{1} \mathrm{O}_{\mathrm{O}^{-}} \mathrm{R}_{2}+\mathrm{HO}-\mathrm{R}_{3} \rightleftharpoons \mathrm{R}_{1}{ }_{\mathrm{O}^{-}} \mathrm{R}_{3}+\mathrm{HO}-\mathrm{R}_{2}
$$

Radical disulfide exchange

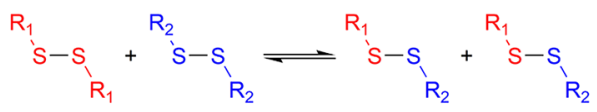

Transalkylation of sulfonium salts

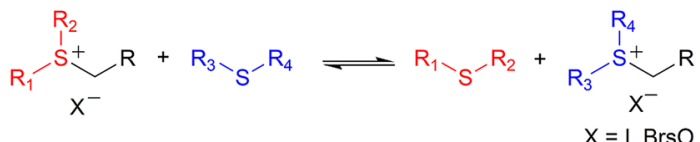

ments of thermoplastics. For instance, satisfying both a zeroshear viscosity higher than $10^{12} \mathrm{~Pa}$ s at $100{ }^{\circ} \mathrm{C}$ (corresponding to an expected ca. $24 \mathrm{~h}$ compression set of $10 \%$ for an elastomer with $G_{0} \sim 1 \mathrm{MPa}$ ) and a zero-shear viscosity lower than $10^{6} \mathrm{~Pa} \cdot \mathrm{s}$ at a processing temperature of $200{ }^{\circ} \mathrm{C}$ implies reaching $E_{\mathrm{a}, \eta}$ values above $200 \mathrm{~kJ} \mathrm{~mol}^{-1}$, that is, far above any currently known vitrimer system. It must also be noted that, in contrast to most 
Scheme 2. Chemical Structures of Poly(1,2,3-triazolium) Networks Obtained through (a) AB + AB and (b) AA + BB Polyaddition Strategies
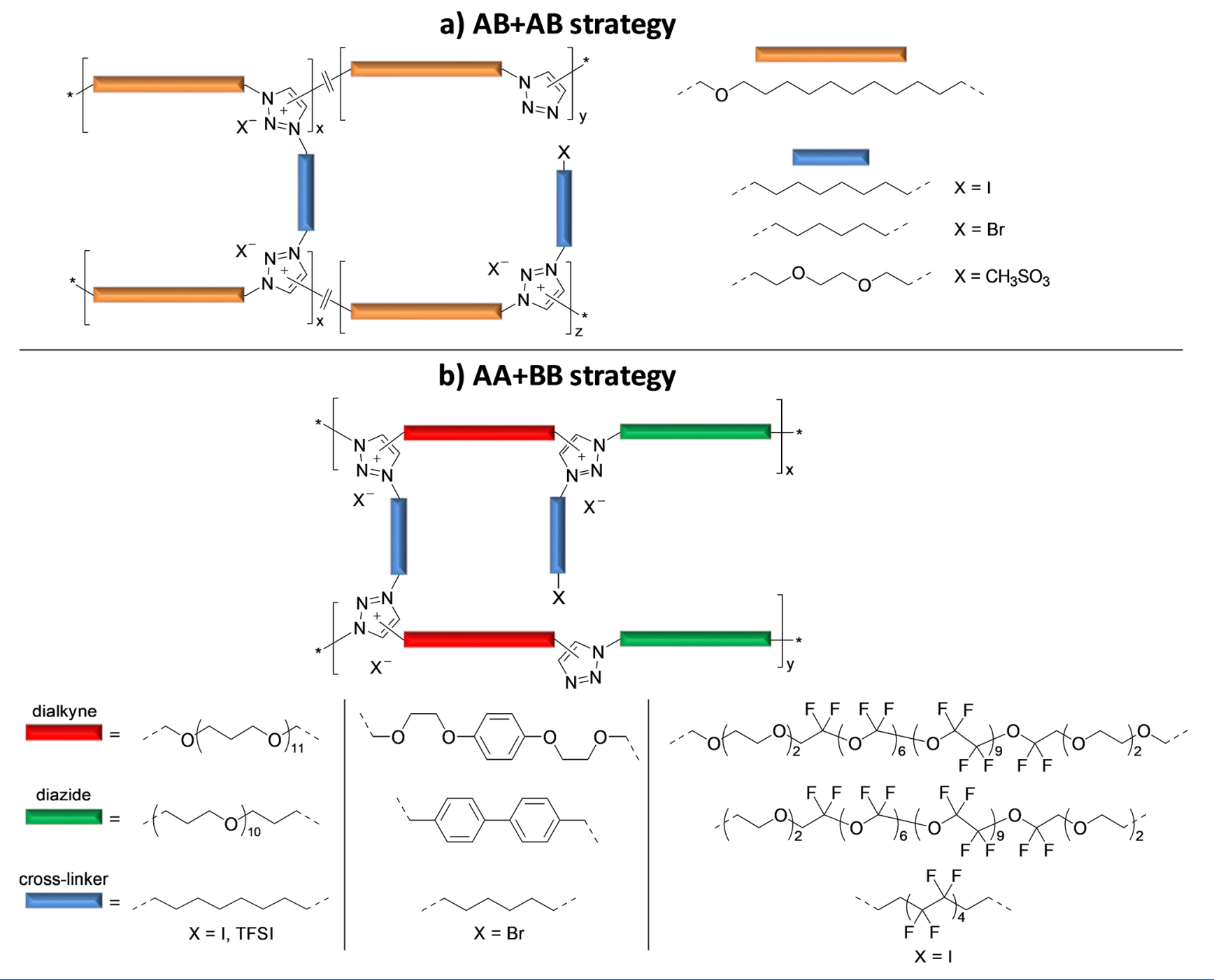

thermoplastics that display a strong shear thinning behavior considerably facilitating their processing, vitrimers have so far only demonstrated a Newtonian behavior although extensive experimental and theoretical investigations involving high shear rates are heavily lacking in this regard. Despite these limitations, many processability opportunities are still offered by current vitrimers, such as surface patterning by embossing, ${ }^{60}$ local reshaping, ${ }^{61}$ or welding. ${ }^{62}$ Such methods can cope with very high viscosities since they involve plastic deformation at very low speeds or moderate extents.

In contrast to vitrimers, most efforts devoted to the design of dissociative networks (Figure 1b) have focused on adduct formation with an association equilibrium constant $K_{\mathrm{a}}=k_{-1} / k$ strongly dependent either on temperature changes (and in this case dictated by the enthalpy of the reversible addition $\Delta_{\mathrm{r}} H^{0}$ ) or on UV-irradiation. Many examples can be found such as heteroDiels-Alder cycloadditions (e.g., furan-maleimide ${ }^{15,16,63}$ or triazolinedione-indole ${ }^{64}$ ) or dimerization reactions of, for example, cinnamic acid, ${ }^{65}$ anthracene, ${ }^{66}$ or coumarin ${ }^{67}$ derivatives. Upon equilibrium shifting toward dissociation of the adduct, the networks can undergo partial decrease of cross-link density and eventually complete de-cross-linking from dynamic networks to liquids beyond a dissociation threshold dictated by the functionality and stoichiometry of the precursors. Correspondingly, these dissociative networks should display four distinct viscoelastic regimes noted from I to IV in Figure $1 b$ ). Note that while such a distinction between different regimes was not necessarily expressed in the same terms in the literature, the description below is a direct consequence of well-known rheological characterization of cross-linking in nonentangled polymers. $^{68}$

In regime I the dissociation level is very low (i.e., low temperatures); the observed cross-link density is maximal, yet cross-link rearrangements through a dissociative mechanism to a very small extent and reassociation are still possible. In such conditions these materials have a rheological behavior indiscernible from vitrimers, with two distinct relaxations spectra $H_{\text {Glass }}(\tau, T)$ and $H_{\text {Network }}(\tau, T)$ and viscosities only driven by exchange kinetics. In regime II, the dissociation levels are higher, the decrease of cross-link density becomes significant (i.e., decrease of amplitude and shift of $H_{\text {Network }}(\tau, T)$ to shorter times), and the viscosities consequently display a stronger temperature dependence. Starting from this point, it appears thus essential to distinguish the temperature dependence of the relaxation times from the temperature dependence of the zeroshear viscosity. In regime III the dissociation levels are such that 
the gel transition is attained, and a dramatic decrease of the zeroshear viscosity is observed. Depending on the nature of the network precursors (e.g., small molecules or multifunctional polymers), a significant decrease of $T_{\mathrm{g}}$ can also be expected (i.e., shift of $H_{\text {Glass }}(\tau, T)$ to much shorter times). Also, the relaxation spectrum $H_{\text {Network }}(\tau, T)$ considerably broadens and decreases in amplitude. Finally, regime IV corresponds to the complete suppression of any effect due to dissociative bonds. The viscosity profile of the precursor analogues deprived of any associating groups is however not necessarily recovered, as complex effects such as weak phase segregation may still occur.

While extensive measurements or extrapolations of zero-shear viscosities over the complete range of viscoelastic regimes are still lacking, Bowman, Kloxin, and co-workers have analyzed the viscoelastic behavior of furan-maleimide molecular-based networks in the vicinity of the gel transition (i.e., regimes II and III in Figure 1b) ${ }^{69}$ Although it is challenging to extrapolate the evolution of zero-shear viscosity from oscillatory experiments especially at lower temperatures, it appears that the transition from regime II to III occurs in a very narrow temperature range (i.e., less than ca. $10^{\circ} \mathrm{C}$ ), and consequently the viscous flow activation energy should be extremely high. Wang and co-workers have performed stress relaxation experiments on furan-functionalized butadiene rubbers cross-linked at low temperature using bismaleimides ${ }^{70}$ and demonstrated that in such conditions the cross-link density does not change significantly (regime I), and the relaxation time of these networks follows an Arrhenius behavior with an overall viscous flow activation energy of ca. $100 \mathrm{~kJ} \mathrm{~mol}^{-1}$. Importantly, in conditions of weak equilibrium (typically $K_{\mathrm{a}}<1000 \mathrm{~L} \mathrm{~mol}^{-1}$ ), the dimerization equilibrium becomes sensitive to the concentration of species and can be shifted toward depolymerization merely by dilution in a nonreactive solvent. ${ }^{71}$

We have extended the recent development of 1,2,3triazolium-based poly(ionic liquid)s (TPILs), ${ }^{72}$ to the versatile one-step solvent- and catalyst-free synthesis of highly crosslinked ionic poly(1,2,3-triazolium) networks. ${ }^{73-77}$ The initial approach relied on the $A B+A B$ step growth polymerization of an $\alpha$-azide- $\omega$-alkyne monomer by Huisgen 1,3-dipolar azidealkyne cycloaddition (HAAC) with concomitant $N$-alkylation of the formed linear poly(1,2,3-triazole)s by bis-halide or bismesylate cross-linkers (Scheme 2a) ${ }^{75,77}$ Further contributions have combined $\mathrm{AA}+\mathrm{BB}$ step growth polymerization of diazide and dialkyne monomers by HAAC with the concomitant crosslinking of the resulting linear poly(1,2,3-triazole)s by $\mathrm{N}$ alkylation using dihalide cross-linkers (Scheme $2 \mathrm{~b}$ ). ${ }^{76,78,79}$ For instance, Nulwala and co-workers have developed cross-linked ionic gas separation membranes by HAAC polyaddition of oligo(trimethylene ether glycol)-based dialkyne and diazide monomers with 1,10-diiododecane cross-linker. ${ }^{76}$ Ion metathesis reaction on the swollen networks to substitute iodide for TFSI counteranions strongly impacted thermomechanical and gas separation properties of the dried membranes. Furthermore, Huang and co-workers have demonstrated self-healing adhesive joints for glass and metals based on a AA + BB strategy involving aromatic diazide and dialkyne monomers with 1,6-dibromohexane as cross-linker. ${ }^{78}$ More recently Améduri and co-workers developed an $\mathrm{AA}+\mathrm{BB}$ strategy toward the synthesis of fluorinated TPIL dynamic networks using perfluoroether-based diazide and dialkyne monomers with aliphatic or perfluorinated diiodide cross-linkers. ${ }^{79}$

Most of these highly cross-linked TPIL ionic networks obtained by using either $\mathrm{AB}+\mathrm{AB}$ or $\mathrm{AA}+\mathrm{BB}$ strategies demonstrate dynamic features evidenced by stress relaxation and creep experiments, with an Arrhenius dependence of the relaxation times $\tau^{*}$ and relatively high kinetic activation energies for catalyst-free dynamic networks $\left(E_{\mathrm{a}, \tau}=140-161 \mathrm{~kJ}\right.$ $\left.\mathrm{mol}^{-1}\right){ }^{75,77,79}$ Insolubility in nonreactive solvents but solubility in reactive alkyl halides, constant cross-link density up to ca. 170 ${ }^{\circ} \mathrm{C}$, and chemical characterization of model compounds initially pointed toward a trans- $\mathrm{N}$-alkylation exchange reaction between the 1,2,3-triazolium cross-links and halide-functionalized dangling chains, with an associative mechanism specific to vitrimers. ${ }^{75}$ However, after further analyses on a series of TPIL dynamic networks with finely tuned composition (i.e., precisely controlled cross-link density and number of iodide-functionalized dangling chains) and by confronting composition of the networks with relaxation times, we established that the trans- $\mathrm{N}$ alkylation exchange mechanism is a two-step dissociative process involving a very small fraction of $\mathrm{C}-\mathrm{N}$ bond breaking and hopping from one location to another without implying concerted exchanges and intermediate adduct formation (Scheme 3). ${ }^{77}$ It must be pointed out that due to the presence

Scheme 3. Two-Step Dissociative Mechanism for Trans- $N$ Alkylation Covalent Exchanges Involving (a) 1,3,4-

Trisubstituted and (b) 1,3,5-Trisubstituted 1,2,3-Triazolium Cross-Links a)
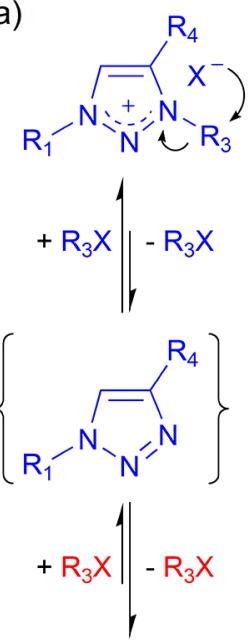

$\overbrace{R_{1}}^{N_{i}=N_{R_{3}}^{R_{4}}} x^{-}$ b)

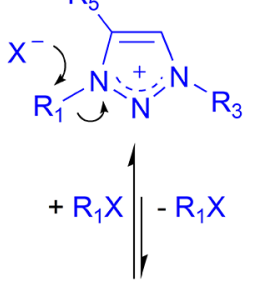

$\left\{\begin{array}{l}\mathrm{R}_{5} \\ \mathrm{~N}_{\mathrm{N}^{\prime}} \mathrm{N}_{\mathrm{R}_{3}}\end{array}\right\}$<smiles>[R]C([Y])(I)C=[R10][H]</smiles><smiles>[R]c1cn([R3])n[n+]1[Tl]</smiles>

of a mixture of 1,3,4- and 1,3,5-trisubstituted 1,2,3-triazolium regioisomers inherent to the copper-free HAAC polyaddition, there is a distinct trans- $N$-alkylation pathway that due to steric hindrance implies exchange of the substituent on the nitrogen atom adjacent to the substituted carbon atom (i.e., exchange of the N-3 and N-1 substituent for 1,3,4- and 1,3,5-trisubstituted 1,2,3-triazolium cross-links, respectively). Recent contributions have extended the realm of trans- $N$-alkylation exchanges to dynamic networks involving anilinium cross-links obtained from the radical copolymerization of 2-hydroxyethyl acrylate, 4- $(N, N-$ dimethylamino)styrene, and a difunctional styrenic cross-linker including a dissociative anilinium linkage $\mathrm{e}^{80,81}$ as well as composite elastomers involving dissociative exchanges of pyridinium cross-links issued from interfacial reactions between poly(2-vinylpyridine) and bromide groups at the surface of 
Scheme 4. Synthesis of TPIL Dynamic Network 7

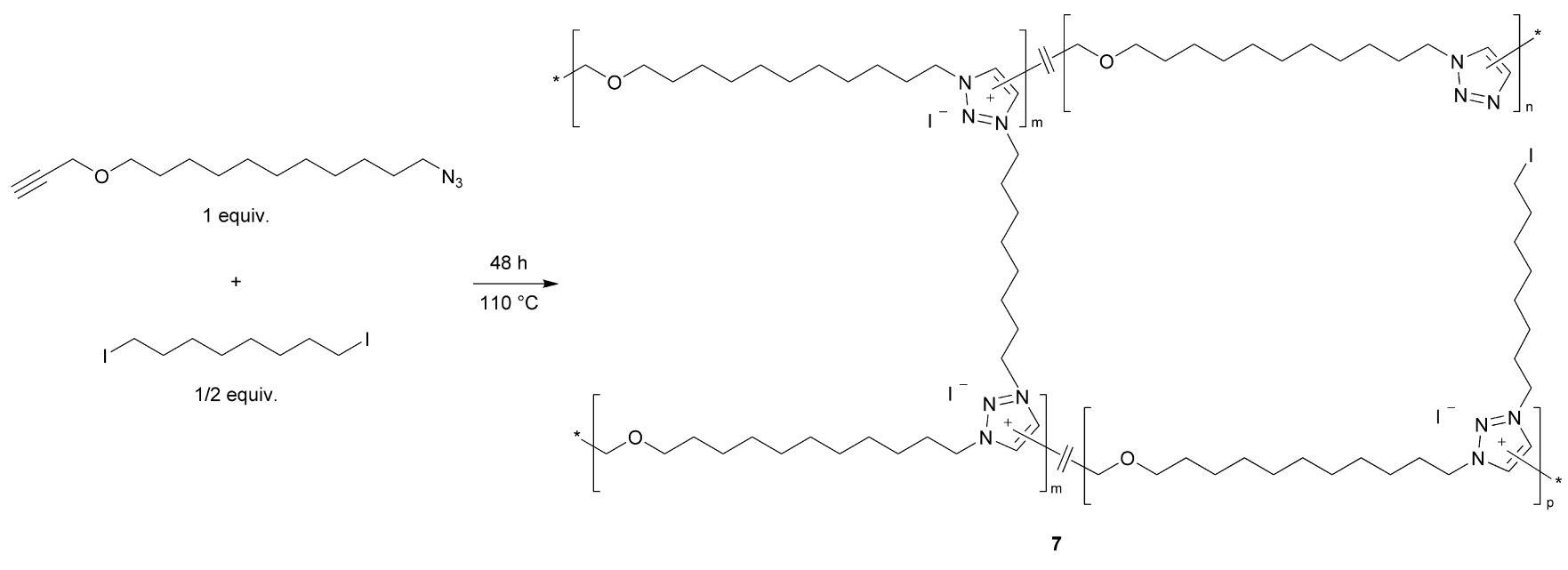

silica. ${ }^{82}$ However, the easy access to materials carrying azide, alkyne, 1,2,3-triazoles, or halide functionalities together with the trifunctional nature of 1,2,3-triazolium groups provides a much broader potential for structural variety compared to generally difunctional pyridinium or anilium groups.

As discussed above regarding regime $\mathbf{I}$ CANs and in agreement with the previous report by Rowan and co-workers on poly(alkylurea-urethane) dynamic networks ${ }^{83,84}$ and by Dichtel, Hillmyer, and co-workers on urethane-containing polymer networks, ${ }^{85}$ it appears thus that the distinction between vitrimers and dissociative networks is not always obvious and that for practical purposes strictly associative exchange mechanisms are not necessarily mandatory to obtain dynamic networks with constant cross-link density. It is however sufficient that the balance of species does not vary appreciably within the considered temperature range. In recent years, many other exchange reactions initially thought to be associative, and in particular those with kinetic activation energies above $100 \mathrm{~kJ}$ $\mathrm{mol}^{-1}$, have been studied in detail by using model compounds and have been found to be in fact dissociative (at least under certain circumstances), ${ }^{11}$ such as transcarbamoylation of hydroxyurethanes ${ }^{35,36,85,86}$ or metathesis of aryl disulfides. ${ }^{52,87}$

Aiming at understanding and improving the properties of TPIL dynamic networks, we found that introducing benzylic groups at both the $N-1$ and $N-3$ positions of 1,2,3-triazolium cross-links greatly modifies the equilibrium between 1,2,3triazole/iodide-functionalized dangling chains and 1,2,3-triazolium adducts compared to previously reported aliphatic TPIL networks. ${ }^{75,77}$ Herein, we chose to exemplify the fast exchange rates of benzylic 1,2,3-triazolium groups by modification of a classical amorphous thermoplastic (i.e., polystyrene) through introduction of complementary 4-propyl-1,2,3-triazole and benzyl iodide pendent groups in two separate copolymers obtained from a common functionalized copolymer precursor. Interchain benzylic 1,2,3-triazolium cross-links detailed below are straightforwardly created by reactive blending of the two copolymers, and we show below that these dissociative networks have a viscoelastic behavior typical of regime II CANs.

To properly compare the linear rheological characterization of vitrimers (or regime I CANs) with dissociative networks (or regime II CANs), we propose a common methodology involving stress relaxations and oscillations at small amplitudes, which enables to characterize the dependence of both the relaxation time and the cross-link density with temperature. The use of time-temperature superposition enables to alleviate the proper fitting of stress relaxations in the case of complex systems, at least when the microphase structuration of the materials remains unchanged in the considered temperature range. This method also enables to distinguish the temperature dependence of relaxation times (kinetic activation energy) and overall viscosity (viscous flow activation energy) and thus offers a more extensive comparison between CANs having distinct topological and chemical variety. In this way, we provide a thorough comparative analysis of the rheological properties of two distinct 1,2,3-triazolium-based dissociative CANs, that is, the previously described TPIL network 7 obtained from aliphatic $\alpha$-azide- $\omega$ alkyne monomer and cross-linker (Scheme 4) ${ }^{75,77}$ and the polystyrene-based TPIL network 6 having benzylic 1,2,3triazoliums cross-links described herein for the first time (Scheme 5).

The short relaxation times associated with benzylic 1,2,3triazolium cross-links and the relatively high glass transition temperature of TPIL dynamic network $6\left(T_{\mathrm{g}} \sim 104{ }^{\circ} \mathrm{C}\right)$ enable for the first time to capture the temperature dependence of both glass transition and network relaxation by using the same rheological tests, thus clearly highlighting that they are independent processes. The moderate temperature dependence of the trans- $N$-alkylation equilibrium ensures that the viscoelastic behavior stays in regime II over the whole temperature range considered (i.e., $120-165{ }^{\circ} \mathrm{C}$ ). This results in a very high viscous flow activation energy $\left(E_{\mathrm{a}, \eta}=230 \mathrm{~kJ}\right.$ $\mathrm{mol}^{-1}$ ) and an ideal compromise of fast processing in the 160$180{ }^{\circ} \mathrm{C}$ temperature range while maintaining a sufficient level of dynamic cross-links and thus high melt strength and facilitated (re)processing.

\section{RESULTS AND DISCUSSION}

Synthesis and Characterization of PS-lodide 2 and PS-1,2,3-Triazoles 3 and 5. To provide TPIL dynamic networks in large quantities, two different scalable approaches were considered to synthesize the complementary linear copolymer precursors (Scheme 5), that is, (1) a postpolymerization multistep chemical modification strategy and (2) a direct copolymerization of a functional monomer strategy. The common precursor of the postpolymerization chemical modification strategy is a statistical copolymer of styrene and 4-chloromethylstyrene ( 1 with ca. 89 and $11 \mathrm{~mol} \%$, respectively) obtained on a $268 \mathrm{~g}$ scale by free radical 
Scheme 5. Synthesis of PS-Iodide 2, PS-1,2,3-Triazoles 3 and 5, and TPIL Dynamic Network 6

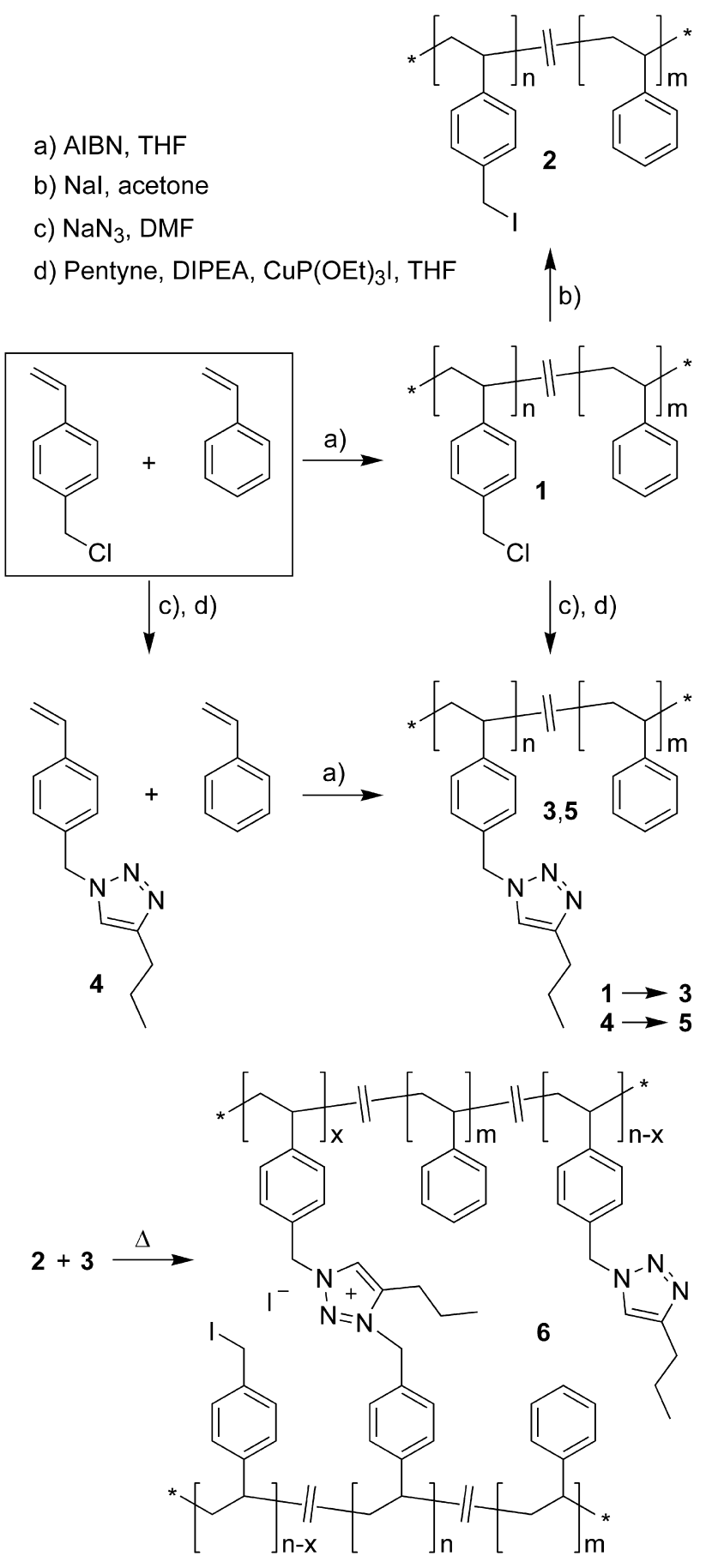

polymerization (FRP) in THF initiated by AIBN at $60^{\circ} \mathrm{C}$. Part of this sample was submitted to iodination reaction using $\mathrm{NaI}$ in acetone (Finkelstein reaction) to afford the corresponding poly(styrene-co-4-iodomethylstyrene) 2 on a 149 g scale. The remaining part of $\mathbf{1}$ was submitted to sequential azidation of the chlorides to generate azidomethyl groups and subsequent copper(I)-catalyzed azide-alkyne cycloaddition (CuAAC) between pendent benzyl azides and 1-pentyne to afford, after liquid-liquid extraction of the copper catalyst, 1,2,3-triazolefunctionalized PS 3 on a $104 \mathrm{~g}$ scale. ${ }^{1} \mathrm{H}$ NMR spectra of PS functional derivatives $\mathbf{2}$ and $\mathbf{3}$ are in perfect agreement with the expected structures (Figures S1 and S2 in the Supporting Information). The quantitative nature of the different chemical modification steps is confirmed by the shifts of the paramethylene signal from $4.63 \mathrm{ppm}$ for PS-chloride 1 to 4.56 and 5.47 ppm for PS-iodide 2 and PS-1,2,3-triazole 3, respectively (Figure 2). Besides, the 1,2,3-triazole proton of 3 can be clearly

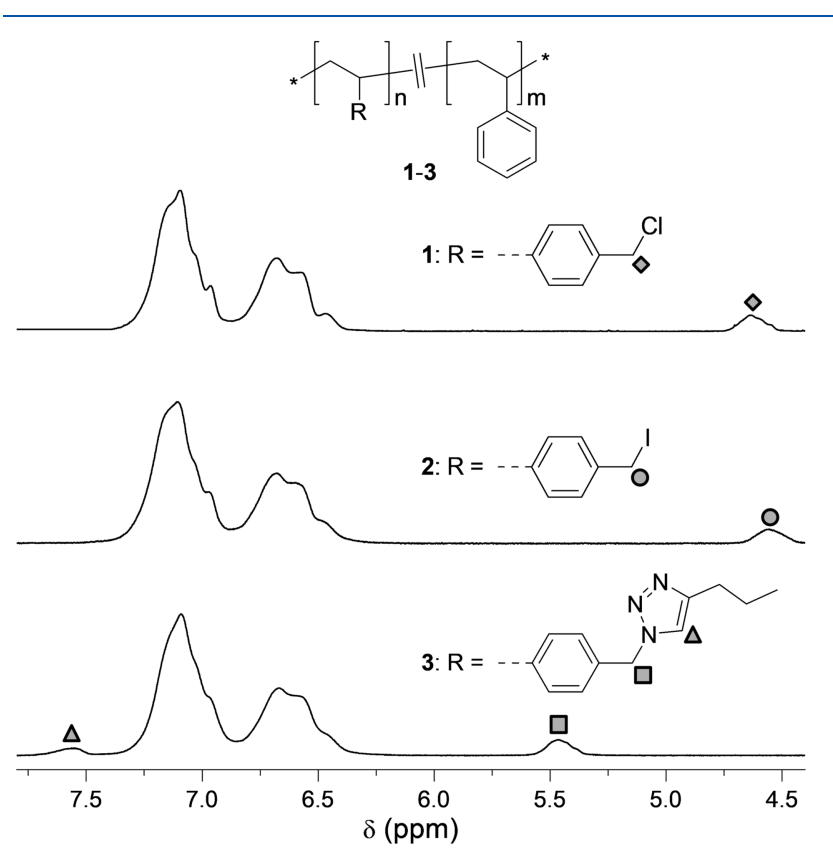

Figure 2. Partial ${ }^{1} \mathrm{H}$ NMR traces (acetone- $d_{6}$ ) of PS-chloride 1 (top), PS-iodide 2 (middle), and PS-1,2,3-triazole 3 (bottom).

seen at $7.56 \mathrm{ppm}$ while no peaks from nonfunctionalized residual units could be discerned by ${ }^{1} \mathrm{H}$ NMR. The content of pendent functionalities (i.e., $11 \mathrm{~mol} \%$ ) is logically maintained unchanged during the chemical modifications sequence. SEC of functionalized PS derivatives 1-3 exhibits monomodal traces having comparable chain dispersities $(\fallingdotseq=1.68-1.78)$ and molar masses $\left(M_{\mathrm{n}}=6.4-7.1 \mathrm{~kg} \mathrm{~mol}^{-1}\right.$ with respect to PS standards) only slightly impacted by the size and chemical nature of the 11 mol \% of functionalized units (Table 1 and Figure S3).

Table 1. Physical Properties of Functional Copolymers 1-3 and 5 and TPIL Dynamic Network 6

$\begin{array}{ccccc}\text { no. } & T_{\mathrm{g}}{ }^{a}\left({ }^{\circ} \mathrm{C}\right) & \left.T_{\mathrm{d} 10^{b}}{ }^{\circ} \mathrm{C}\right) & M_{\mathrm{n}}{ }^{c}\left(\mathrm{~kg} \mathrm{~mol}^{-1}\right) & \oplus^{c} \\ \mathbf{1} & 104 & 355 & 6.4 & 1.73 \\ \mathbf{2} & 93 & 270 & 6.8 & 1.78 \\ \mathbf{3} & 83 & 355 & 7.1 & 1.68 \\ \mathbf{5} & 83 & 360 & 8.9 & 1.53 \\ \mathbf{6} & 104 & 320 & & \end{array}$

${ }^{a}$ Determined by DSC. ${ }^{b}$ Temperature for $10 \%$ weight loss determined by TGA. ${ }^{c}$ Determined by $\mathrm{SEC}$ in $\mathrm{CHCl}_{3}$.

Because of the potential occurrence of iodine transfer polymerization, ${ }^{88}$ the direct copolymerization of 4-iodomethylstyrene could not be considered, and this alternative strategy was only applied to the synthesis of PS-1,2,3-triazole 5 from the copolymerization of a styrenic monomer carrying a pendent 1,2,3-triazole group. With this aim, 4-propyl-1-(4vinylbenzyl)-1,2,3-triazole monomer 4 (Scheme 5) was synthesized by CuAAC between 4-azidomethylstyrene and 1pentyne with DIPEA as base and $\mathrm{CuI}(\mathrm{POEt})_{3}$ as catalyst. 
Monomer 4 was obtained in $87 \%$ yield and $17 \mathrm{~g}$ scale after purification by column chromatography. Its structure and purity were confirmed by ${ }^{1} \mathrm{H}$ and ${ }^{13} \mathrm{C}$ NMR spectroscopy (Figures S4 and S5) and high-resolution electrospray ionization mass spectrometry. Statistical copolymer 5, a structural analogue of copolymer 3 obtained by the postpolymerization multistep chemical modification strategy, was obtained on a $17 \mathrm{~g}$ scale by FRP of styrene and 1,2,3-triazole-functionalized monomer 4 performed in THF at $60{ }^{\circ} \mathrm{C}$ with AIBN as initiator. ${ }^{1} \mathrm{H}$ NMR spectra of $\mathbf{3}$ and $\mathbf{5}$ are almost identical (Figure S6) and so are the contents of pendent 1,2,3-triazole groups (i.e., ca. $11 \mathrm{~mol} \%$ ). However, SEC measurements show slightly higher $M_{n}$ and lower $Ð$ values for $\mathbf{5}$ compared to $\mathbf{1 - 3}$ (Table 1 and Figure S3). It is worth noting that functional copolymers 2,3 , and 5 have $M_{n}$ values well below entanglement (ca. $20 \mathrm{~kg} \mathrm{~mol}^{-1}$ for PS). ${ }^{68}$

Thermal properties of functional linear precursors $\mathbf{1 - 3}$ and 5 (Table 1) were evaluated by differential scanning calorimetry (DSC) and thermogravimetric analysis (TGA). It is well-known that $T_{\mathrm{g}}$ of polymer chains can be significantly impacted by low molar masses, the nature of the chain ends, and the presence of different comonomer units. For comparison, while $T_{\mathrm{g}}$ of a PS with $M_{\mathrm{n}}=7.0 \mathrm{~kg} \mathrm{~mol}^{-1}$ can be estimated at $89^{\circ} \mathrm{C}$, 89 PSchloride 1 and PS-iodide 2 have higher $T_{\mathrm{g}}$ values of 104 and 93 ${ }^{\circ} \mathrm{C}$, respectively. Conversely, PS-1,2,3-triazoles 3 and 5 display lower $T_{\mathrm{g}}$ values of $83{ }^{\circ} \mathrm{C}$ that could be due to the plasticizing effect of 4-propyl-1,2,3-triazole pendent groups. PS-chloride 1 and PS-1,2,3-triazoles 3 and 5 exhibit comparable 10\% weight loss temperature $\left(T_{\mathrm{d} 10}\right)$ values of ca. $355^{\circ} \mathrm{C}$ (Figure S7), thus showing the limited impact of the low fraction of functionalized units (i.e., ca. $11 \mathrm{~mol} \%$ ). As could be expected, almost identical $T_{\mathrm{g}}$ and $T_{\mathrm{d} 10}$ values were observed for PS-1,2,3-triazoles 3 and $\mathbf{5}$ obtained respectively by postpolymerization chemical modifications of 1 and by direct copolymerization of styrene and 1,2,3-triazole monomer 4. PS-iodide 2 has the lowest thermal stability of the series $\left(T_{\mathrm{d} 10}=270^{\circ} \mathrm{C}\right)$ due to the higher reactivity of benzyl iodides that can promote different side reactions consequent to the cleavage of the carbon-iodide bond. ${ }^{90}$ As PS1,2,3-triazole 3 was synthesized in larger quantities (i.e., ca. $100 \mathrm{~g}$ scale) than 5, and involved fewer synthetic steps involving exclusively commercial compounds, only 3 was considered further for the preparation of TPIL dynamic network 6 (Scheme 5).

Preparation of TPIL Dynamic Network 6. Most relevant polymer networks containing dynamic covalent cross-links are obtained by using conventional techniques of thermosetting materials that are strongly connected to applications as adhesives, coatings, or matrices for composite materials. Most systems are bicomponent and involve low-viscosity, polyfunctionnal precursors with optional cosolvents or catalysts. The exchangeable groups can either be formed during the curing reaction or already be constitutive of the precursors thus involving curing reactions forming nondynamic bonds. The lack of melt strength at the early stages of the polymerization and the very high viscosities beyond the gel point can be challenging issues for many processes designed for thermoplastics that often involve a first preprocessing of the materials into pellets, films, or sheets and a subsequent curing process by, for example, reshaping, injection, or calendaring. In some rare cases, vitrimers display sufficiently fast exchange reactions to allow extensive processing with high-shear extrusion, but at the cost of reduced creep resistance at low temperatures. ${ }^{55,91,92}$ An alternative strategy relies on specific protection of reactive units, leaving for instance only difunctional monomer units amenable to polymerization into highly processable linear polymers. Heuts, Goossens, and co-workers have used such strategy to develop linear PBTs as vitrimer precursors containing benzal-protected pentaerytrithol units. ${ }^{29}$ In a subsequent deprotection step (either chemically or at high temperature) diols become available and afford dynamic cross-linking of the PBT network in the presence of zinc(II) catalyst. ${ }^{32}$ Herein, we initially aimed at mixing a 1:1 (w/w) blend of complementary PS-iodide 2 and PS-1,2,3-triazole 3 that corresponds to a molar ratio $R=$ [iodide $] /[1,2,3$-triazole $]=0.9$ (Scheme 5$)$. By analogy with the trans- $N$-alkylation reactivity previously reported for aliphatic TPIL dynamic networks, ${ }^{75,77}$ a sufficiently delayed cross-linking was expected to allow for a three-step process consisting in (1) melt-blending the PS compounds by extrusion at ca. 140-160 ${ }^{\circ} \mathrm{C}$, (2) subsequent injection of samples, and (3) a final postcuring step. Yet, the reactivity of benzyl iodides proved significantly faster than previously reported aliphatic TPIL dynamic networks and thus prevented this sequential approach. For practical reasons, we resorted to coprecipitating $\mathbf{2}$ and $\mathbf{3}$ to blend them intimately, followed by drying and initial curing of the resulting powder 6 under vacuum at $120^{\circ} \mathrm{C}$ for $15 \mathrm{~h} . T_{\mathrm{g}}$ of TPIL dynamic network 6 is $104{ }^{\circ} \mathrm{C}$ and is higher than those of its parent linear precursors 2 and $3\left(T_{\mathrm{g}}=93\right.$ and $83{ }^{\circ} \mathrm{C}$, respectively). This is related to the formation of covalent 1,2,3-triazolium cross-links by $N$-alkylation reaction between 1,2,3-triazole and benzyl iodide pendent groups. $T_{\mathrm{d} 10}$ of the TPIL dynamic network $6\left(T_{\mathrm{d} 10}=320{ }^{\circ} \mathrm{C}\right)$ is logically intermediate between $T_{\mathrm{d} 10}$ values of the parent precursors (i.e., $T_{\mathrm{d} 10}=270$ and $355^{\circ} \mathrm{C}$ for 2 and 3 , respectively) and well above the temperatures used to perform the curing and thermomechanical characterization of vitrimer materials. Because of the low content of 1,2,3-triazolium units and the the fact that poly(1,2,3-triazole $)$ have a better stability than their triazolium analogues, $T_{\mathrm{d} 10}$ of $\mathbf{6}$ is higher than values previously reported for TPIL-iodide homopolymers that exhibit $T_{\mathrm{d} 10}$ values ranging from 203 to $255^{\circ} \mathrm{C} .^{72}$

Compaction at room temperature of the linear precursors 2 and 3 and of the previously annealed TPIL dynamic network 6 yielded as expected fragile and opaque samples with weak cohesion between grains. Nevertheless, while linear PS precursors 2 and 3 quickly turned into viscous liquids above $100{ }^{\circ} \mathrm{C}$, the 1,2,3-triazolium network 6 did not display any flow after several hours at $130^{\circ} \mathrm{C}$, thus demonstrating as expected the formation of 1,2,3-triazolium cross-links with slow exchange kinetics at this temperature. However, at $160^{\circ} \mathrm{C}$, the compacted powder of 6 quickly sintered into tough transparent disks (Figure 3), thus demonstrating unexpectedly low viscosity. Such a dramatic decrease of viscosity over a $30{ }^{\circ} \mathrm{C}$ increase in temperature indicates a very high viscous flow activation energy and prompted us to carry out a thorough thermomechanical

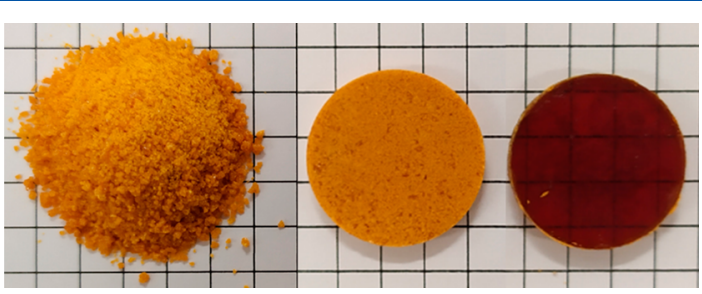

Figure 3. Mixtures of linear precursors 2 and 3 before (left) and after (middle) compaction at room temperature and (right) after compaction for $15 \mathrm{~min}$ at $160{ }^{\circ} \mathrm{C}$. Dimensions of the tiles are $0.5 \times$ $0.5 \mathrm{~cm}^{2}$. 
characterization of TPIL dynamic network 6 and its linear precursors by rheology.

Synthesis and Chemical Characterization of TPIL Dynamic Network 6. PS-iodide 2 and PS-1,2,3-triazole 3 display the conventional rheological behavior of unentangled linear polymers. Master curves built through time-temperature superposition of small-amplitude oscillatory shear (SAOS) data from 110 to $150^{\circ} \mathrm{C}$ (Figure 4) and referenced at $T_{0}=T_{\mathrm{g}}+40 \mathrm{~K}$
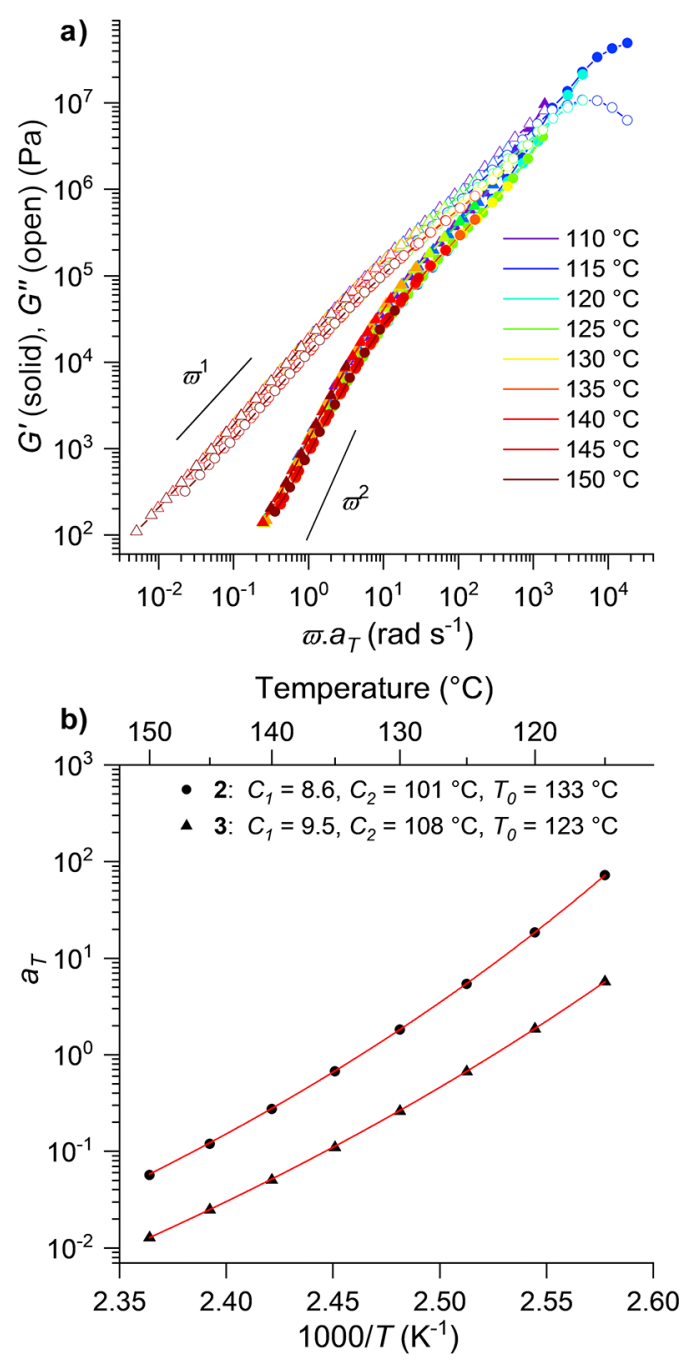

Figure 4. (a) Master curves of PS-iodide 2 (circles) and PS-1,2,3triazole 3 (triangles) obtained by SAOS data from 110 to $150{ }^{\circ} \mathrm{C}$ and referenced at $T_{\text {ref }}=T_{\mathrm{g}}+40 \mathrm{~K}$. (b) Corresponding $a_{\mathrm{T}}$ shift factors and WLF fits using $T_{0}=T_{\mathrm{g}}+40 \mathrm{~K}$ and $\log \left(a_{T}\right)=-\left[C_{1}\left(T-T_{0}\right)\right] /\left[C_{2}+(T\right.$ $\left.-T_{0}\right)$ ] for PS-iodide 2 (circles) and PS-1,2,3-triazole 3 (triangles).

are overlapping and display a terminal relaxation immediately above the glass transition as evidenced by the slopes $G^{\prime} \sim \omega^{2}$ and $G^{\prime \prime} \sim \omega^{1}$. The corresponding shift factors were fitted with the Williams-Landel-Ferry (WLF) model, $\log \left(a_{T}\right)=-\frac{C_{1}\left(T-T_{0}\right)}{C_{2}+\left(T-T_{0}\right)}$, and demonstrate close $C_{1}$ and $C_{2}$ parameters (Figure $4 \mathrm{~b}$ ). Correspondingly, $C_{1}^{\mathrm{g}}$ and $C_{2}^{\mathrm{g}}$ parameters referenced at $T_{0}=T_{\mathrm{g}}$ are 14.2 and $61.0^{\circ} \mathrm{C}$ and 15.1 and $68.0^{\circ} \mathrm{C}$ for 2 and 3, respectively, which is significantly different from polystyrene constants (i.e., $C_{1, \mathrm{PS}}^{\mathrm{g}}=17.4^{\circ} \mathrm{C}$ and $C_{2, \mathrm{PS}}^{\mathrm{g}}=51.6^{\circ} \mathrm{C}^{93}$ ) and could be related to the relatively broad chain dispersities and the low molar masses of 2 and 3.
Time monitoring with SAOS at a constant frequency of $1 \mathrm{~Hz}$ for TPIL dynamic network 6 upon successive temperature increments from 120 to $165{ }^{\circ} \mathrm{C}$ shows dramatic decreases of storage $\left(G^{\prime}\right)$ and loss $\left(G^{\prime \prime}\right)$ moduli (Figure 5). Up to ca. $135^{\circ} \mathrm{C}$,

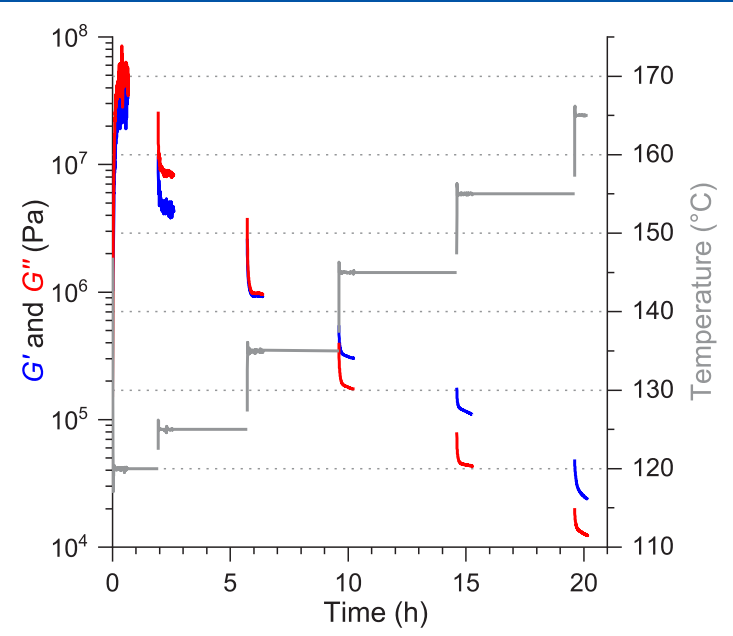

Figure 5. Time monitoring of temperature (gray lines), storage modulus (blue lines), and loss modulus (red lines) for TPIL dynamic network 6 during the application of gradual temperature increments ranging from 120 to $165^{\circ} \mathrm{C}$.

the high values of both moduli and the predominance of $G^{\prime \prime}$ are typical of the glassy regime. Above ca. $140^{\circ} \mathrm{C}$, the predominance of $G^{\prime}$ is distinctive of cross-linked networks, yet with a cross-link density strongly decreasing at higher temperatures, thus pointing clearly toward a regime II CAN behavior (Figure 1b). Below $150{ }^{\circ} \mathrm{C}$, the moduli stabilize within a few minutes after each temperature increment, thus demonstrating fast equilibrium reactions. However, above $150{ }^{\circ} \mathrm{C}$ a continuous decrease of moduli with time might indicate occurrence of plausible side reactions initiated by the homolytic cleavage of carbon-iodide bonds that could yield to permanent de-crosslinking. This observation might also be linked to the small number-average polymerization degree $\left(X_{n}\right)$ and broad dispersity (i.e., presence of small chains providing few 1,2,3triazolium cross-links) of linear precursors 2 and 3 . Besides, the formation of cyclic species or dimerized polymer chains that do not participate in the network elasticity might contribute to the decrease of moduli at higher temperatures.

Thorough measurement of the temperature-dependent equilibrium constants between iodide/1,2,3-triazole and 1,2,3triazolium species is extremely challenging as the most reliable technique to access composition of TPIL networks, that is, XPS analysis, cannot be performed in situ at high temperatures. We were however able to compare two samples of TPIL dynamic network 6 after very different annealing conditions. The first sample (Figure 6a) was annealed at $170{ }^{\circ} \mathrm{C}$ and vitrified by quenching in liquid nitrogen to prevent any change in the network composition upon cooling. The second sample (Figure 6b) was annealed at $170{ }^{\circ} \mathrm{C}$ and slowly cooled to room temperature at $0.5{ }^{\circ} \mathrm{C} \mathrm{min}{ }^{-1}$ to maximize any change in the equilibrium composition before vitrification. Because XPS is a surface characterization technique (with ca. $10 \mathrm{~nm}$ penetration depth using X-rays with normal incidence), samples were freshly cut parallel to their surface with a razor blade. High-resolution $I_{3 \mathrm{~d} 5 / 2}$ spectra taken at different locations and averaged to get a faithful representation of the bulk composition enabled a 

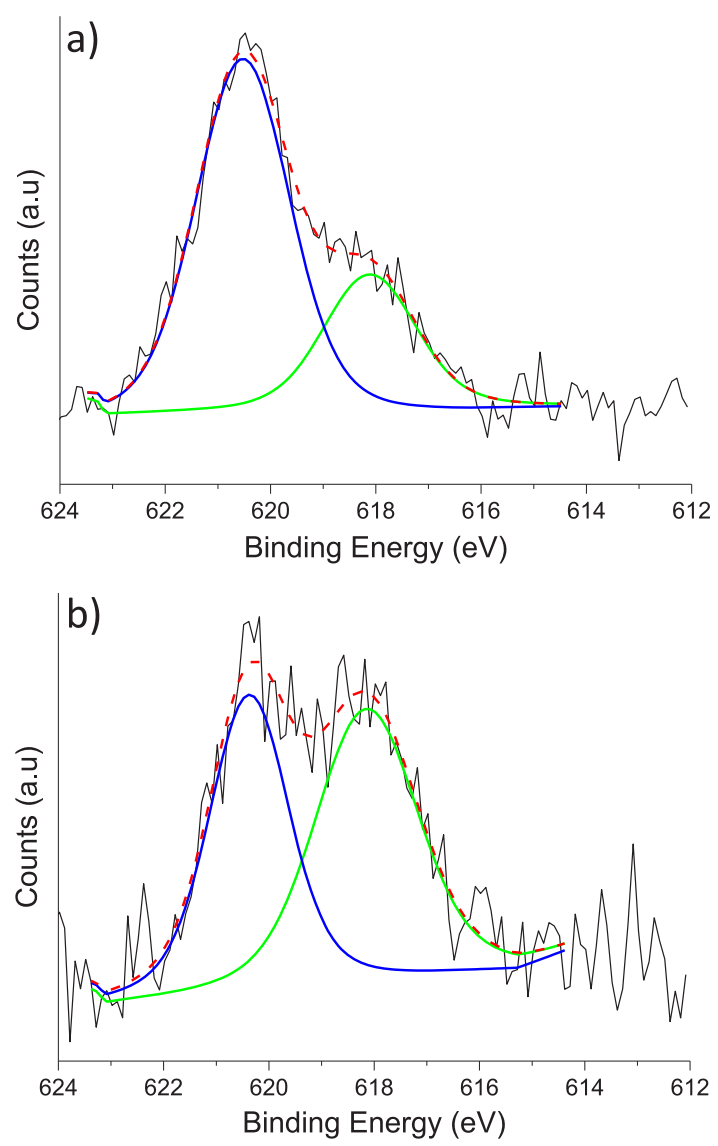

Figure 6. High-resolution $I_{3 \mathrm{~d} 5 / 2}$ spectra of TPIL dynamic network 6: (a) equilibrated at $170{ }^{\circ} \mathrm{C}$ and quenched in liquid nitrogen or (b) cooled from $170{ }^{\circ} \mathrm{C}$ to room temperature at $0.5 \mathrm{~s} \mathrm{~min}^{-1}$. The peak fitting (red lines) was realized assigning two signals for neutral benzyl iodides (blue lines) and iodide anions associated with 1,2,3-triazolium groups (green lines).

quantitative distinction between unreacted pendent benzyl iodides (limiting reagent) and iodide counteranions associated with 1,2,3-triazolium species leading to the extent of the $\mathrm{N}$ alkylation reaction: $x=\frac{\left[\mathrm{I}^{-}\right]}{[\text {benzyl iodide }]+\left[\mathrm{I}^{-}\right]}$(see Figure 6 and experimental details in the Supporting Information). Remarkably distinct $x$ values were obtained depending on the cooling conditions as $x$ is ca. $28 \%$ and $54 \%$ for the network quenched at $170{ }^{\circ} \mathrm{C}$ and the network slowly cooled below $T_{\mathrm{g}}$, respectively. This is strong evidence that the 1,2,3-triazole/1,2,3-triazolium equilibrium is shifting toward de- $N$-alkylation at higher temperatures, in fair agreement with the decrease in cross-link density inferred from temperature-jump rheology experiments (Figure 5).

Comparative Characterization of Network Relaxations in TPIL Dynamic Networks 6 and 7. Frequency sweeps and stress relaxation experiments were performed at temperatures ranging from 110 to $170{ }^{\circ} \mathrm{C}$ on TPIL dynamic networks 6 and 7 (Figure 7). ${ }^{75,77}$ For 6, at high frequencies and low temperatures the upturn of $G^{\prime}$ and $G^{\prime \prime}$ (Figure 7a) indicates the glass-to-rubber transition $H_{\text {Glass }}(\tau, T)$. At intermediate frequencies, the presence of elastic plateaus spanning several decades of frequency, with moduli decreasing from $600 \mathrm{kPa}$ at $125{ }^{\circ} \mathrm{C}$ to $40 \mathrm{kPa}$ at $165{ }^{\circ} \mathrm{C}$ (Figure $7 \mathrm{c}$ ), confirms a behavior typical of dissociative networks and an absence of the sol-gel transition. At low frequencies (i.e., $\omega<10^{-1} \mathrm{rad} \mathrm{s}^{-1}$ ) a crossover visible above $145{ }^{\circ} \mathrm{C}$ identifies the rubber-to-liquid transition of dynamic networks $H_{\text {Network }}(\tau, T)$ clearly separated from the glassto-rubber transition. The stress relaxation data (Figure $7 \mathrm{~b}$ ) appear in good accordance with the SAOS experiments, also showing well-defined plateau moduli and relaxations. Data measured at short times (i.e., $t<1 \mathrm{~s}$ ) are affected by inertia and compliance issues for temperatures close to $T_{\mathrm{g}}$ and were thus discarded. It is worth noting that the log-log representation of stress relaxation reveals a deviation from purely monoexponential decays at longer experimental times. The linear slopes $G(t)$ $\sim t^{-p}$ with $p \approx 1$ at longer times indicate additional slow modes of relaxation that are typically well-captured with a power law distribution and are often encountered in systems displaying phase separation. ${ }^{94-96}$ A weak phase separation between ionicrich and ionic-poor domains is indeed plausible. ${ }^{97}$ The relaxation moduli were thus fitted with an initial monoexponential relaxation $\left(G_{0}, \tau^{*}\right)$ and a sum of exponentials with relaxation times $\tau>\tau^{*}$ corresponding to the decomposition of a power law in Prony series:

$$
G(t)=G_{0} \mathrm{e}^{-t / \tau *}+\sum_{i=1}^{N} G_{i} \mathrm{e}^{-t / \tau_{i}}
$$

with $\tau_{\mathrm{i}}=\tau^{*} \times 2^{i}$ the $i^{\text {th }}$ harmonics of the relaxation time and $G_{i>0}=K\left(\frac{\tau_{i}}{\tau^{*}}\right)^{-p}$ the corresponding power-law decay. The $p$ parameters being taken directly from the slopes of $G(t)$, this is overall a three-parameter model $\left(G_{0}, \tau^{*}, K\right)$ that fits remarkably well the data (Figure $7 \mathrm{~b}$ and Table $S 1$ ).

In stringent contrast to 6 , the aliphatic TPIL dynamic network 7 displays an evolution of $G^{\prime}$ independent of the frequency for all temperatures (Figure $7 \mathrm{~d}$ ), indicating that the sample is probed sufficiently above $T_{\mathrm{g}}\left(T_{\mathrm{g}}=23^{\circ} \mathrm{C}\right)$ and that the rubber-to-liquid relaxation times are much higher than for network 6 . Even at 170 ${ }^{\circ} \mathrm{C}$, hints of a network relaxation are barely discernible from the upturn of $G^{\prime \prime}$ at low frequencies. More importantly, the storage moduli are only slightly changing with the temperature (Figure $7 \mathrm{f}$ ), varying from $1.9 \mathrm{MPa}$ at $120^{\circ} \mathrm{C}$ to $2.4 \mathrm{MPa}$ at $160^{\circ} \mathrm{C}$, which is consistent with a constant cross-link density in this temperature range typical of associative CANs (i.e., vitrimers). Stress relaxations (Figure 7e) display correspondingly the same elastic plateaus at short times and enable to characterize the network relaxation at longer times. In contrast to TPIL dynamic network 6, relaxation moduli of 7 are well fitted with stretched exponential decays

$$
G(t)=G_{0} e^{-\left(t / \tau^{*}\right)^{\beta}}
$$

with $\beta$ parameters between 0.7 and 0.8 (Table S2), thus demonstrating relatively narrow distributions of relaxation times.

Benefits of Time-Temperature Superposition to Analyze the Temperature Dependence of Viscoelastic Properties. Given the different viscoelastic behaviors of TPIL dynamic networks 6 and 7, the most convenient method to compare the temperature dependence of these systems is therefore to construct master curves. While different definitions have been proposed, ${ }^{98,99}$ we consider here the superposition $G^{*}\left(\omega, T_{0}\right)=\left(1 / b_{T, \text { Network }}\right) G^{*}\left(\omega a_{T, \text { Network }}, T\right)$ and $G\left(t, T_{0}\right)=\frac{1}{b_{T}} G\left(\frac{t}{a_{T}}, T\right)$ where the $b_{T, \text { Network }}$ shift factors indicate the variation of cross-link density with temperature, $b_{T, \text { Network }}=G_{\text {Network }}(T) / G_{\text {Network }}\left(T_{0}\right)$, and the $a_{T, \text { Network }}$ shift factors indicate the averaged variation of relaxation times with 

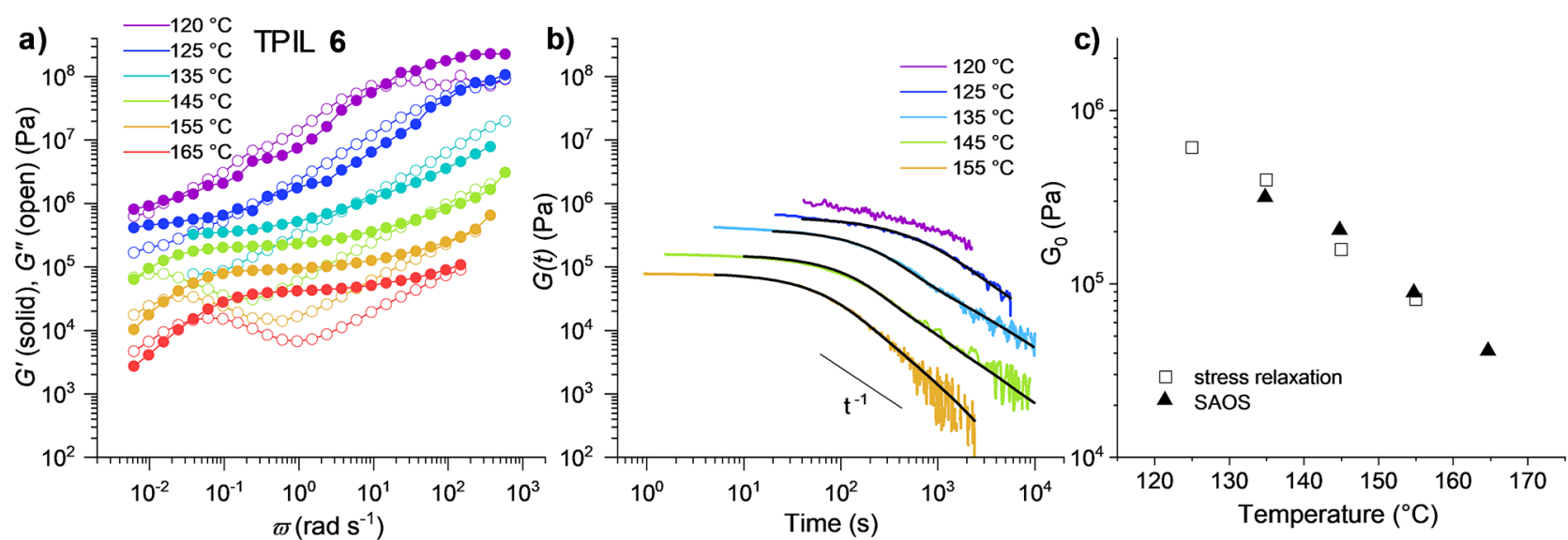

d)

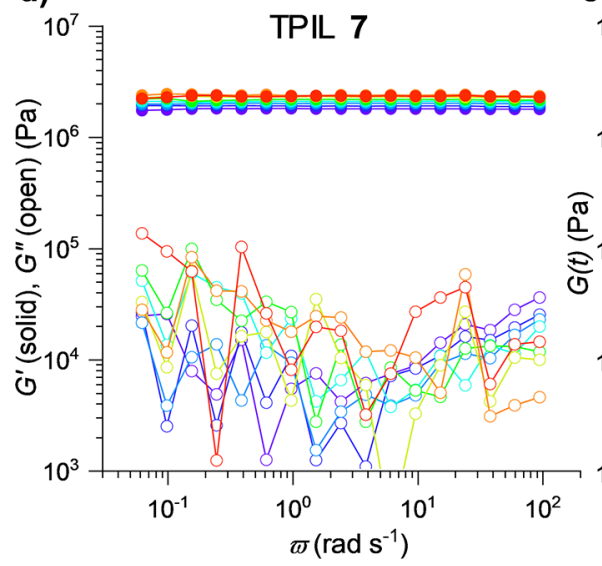

e)

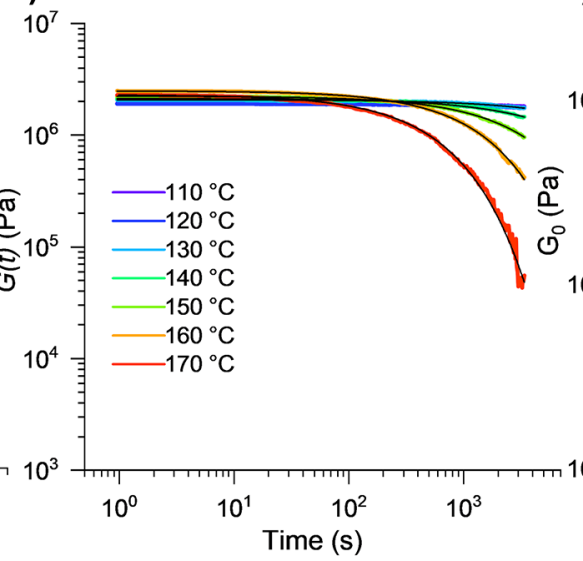

f)

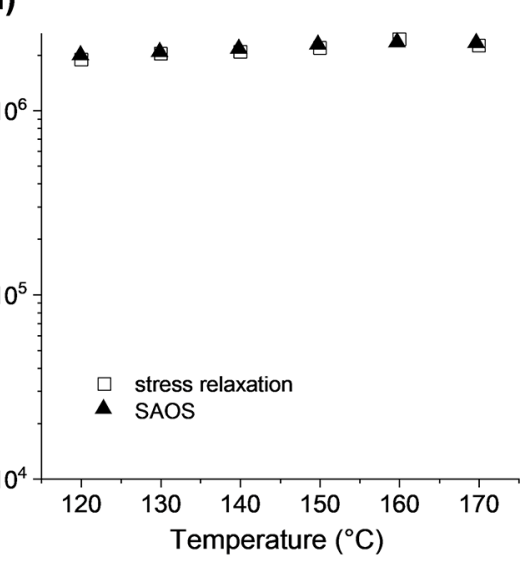

Figure 7. Storage $\left(G^{\prime}\right)$ and loss $\left(G^{\prime \prime}\right)$ moduli as a function of frequency for $\mathbf{6}(\mathrm{a})$ and 7 (d) equilibrated after temperature increments. Stress relaxation experiments $\left(0.25 \%\right.$ strain) performed on 6 (b) and 7 (e) at temperatures ranging from 125 to $155{ }^{\circ} \mathrm{C}$ and fitted (black solid lines) by using multiexponential decays (eq 1) or stretched exponential decays (eq 2). Plateau moduli for 6 (c) and 7 (f) determined from stress relaxation experiments (open squares) and SAOS (solid triangles).

temperature, $a_{T, \text { Network }}=\left\langle\tau_{\text {Network }}(T)\right\rangle /\left\langle\tau_{\text {Network }}\left(T_{0}\right)\right\rangle$. Figure 8 shows the frequency sweep and stress relaxation master curves obtained for TPIL dynamic network 6 by adjusting the data at low frequencies (crossover regime for SAOS in Figure 8a and main relaxation event for stress relaxations in Figure $8 b$ highlighted by dashed rectangles) to capture the variations of $H_{\text {Network }}(\tau, T)$. The corresponding $a_{T, \text { Network }}$ shift factors calculated from stress relaxation data (red circles in Figure 8c) and SAOS (red triangles in Figure 8c) follow a common behavior and, as expected from relaxation events related to chemical exchanges, can be fitted with an Arrhenius law: $a_{T, \text { Network }}=A \mathrm{e}^{E_{2} \tau / R T}$, with a kinetic activation energy $E_{\mathrm{a}, \tau}=129 \mathrm{~kJ}$ $\mathrm{mol}^{-1}$. The corresponding stress relaxation master curve for TPIL dynamic network 7 is displayed in Figure $8 \mathrm{~d}$ and the shift factors in Figure 8e (see details in Table S2). The kinetic activation energy of 7 is $E_{\mathrm{a}, \tau}=155 \mathrm{~kJ} \mathrm{~mol}^{-1}$, in excellent agreement with previously reported value. ${ }^{75}$

The cross-link density results from a complex interplay between the $N$-alkylation equilibrium and thus the effective extent of cross-link reaction and the average functionality of the PS precursors 2 and 3 that determines the critical extent of reaction at the gel point. In the temperature range probed (i.e., $\left.125-165^{\circ} \mathrm{C}\right)$, the $b_{T, \text { Network }}$ shift factors of network 6 also follow an exponential law, that is, $b_{T, \text { Network }}=\frac{G_{\text {Network }}(T)}{G_{\text {Network }}\left(145^{\circ} \mathrm{C}\right)} \propto$ $\mathrm{e}^{E_{\mathrm{a}, \text { Network }} / R T}$. It is worth noting that such a behavior is not expected to extend over a much larger temperature range due to the dissociative nature of the trans- $N$-alkylation reaction. At lower temperatures, for instance, the cross-link density should eventually reach a maximum and the $b_{T, \text { Network }}$ shift factor should plateau up (i.e., regime I CANs). Conversely, at higher temperatures the network may eventually de-cross-link with a dramatic decrease of $b_{T, \text { Network }}$ and eventually an absence of elastic plateau and thus impossibility to carry out timetemperature superposition analysis (i.e., regime III CANs). Within the $125-165{ }^{\circ} \mathrm{C}$ range that corresponds to regime II CANs, it is possible that the effective cross-link density of the network varies as the association constant $K_{\mathrm{a}}$ and thus follows a Van't Hoff model: $K_{\mathrm{a}}(T)=\mathrm{e}^{-\Delta_{\mathrm{r}} G \circ / R T} \sim \mathrm{e}^{-\Delta_{\mathrm{r}} H \circ / R T}$. This could explain the exponential law found for $b_{T}$, with $E_{\mathrm{a}, \text { Network }} \approx$ $-\Delta_{\mathrm{r}} H^{0}$.

The zero-shear viscosity of TPIL dynamic network 6, if estimated solely from the $H_{\text {Network }}$ relaxation, could then be expressed as

$$
\begin{gathered}
\frac{\eta_{0}(T)}{\eta_{0}\left(145^{\circ} \mathrm{C}\right)}=\frac{G_{\text {Network }}(t) \tau_{\text {Network }}(T)}{G_{\text {Network }}\left(145^{\circ} \mathrm{C}\right) \tau_{\text {Network }}\left(145^{\circ} \mathrm{C}\right)} \\
=a_{T, \text { Network }} b_{T, \text { Network }} \sim \mathrm{e}^{E_{\mathrm{a}, \tau} / R T} \mathrm{e}^{E_{\mathrm{a}, \text { Network }} / R T}
\end{gathered}
$$

The overall viscous flow activation energy is thus $\mathrm{E}_{\mathrm{a}, \eta}=\mathrm{E}_{\mathrm{a}, \tau}+$ $\mathrm{E}_{\mathrm{a}, \text { Network }}=232 \mathrm{~kJ} \mathrm{~mol}^{-1}$. Comparative analysis of $b_{T}$ shift factor on network 7 (Figure 8e) displays as expected a very weak 
a)

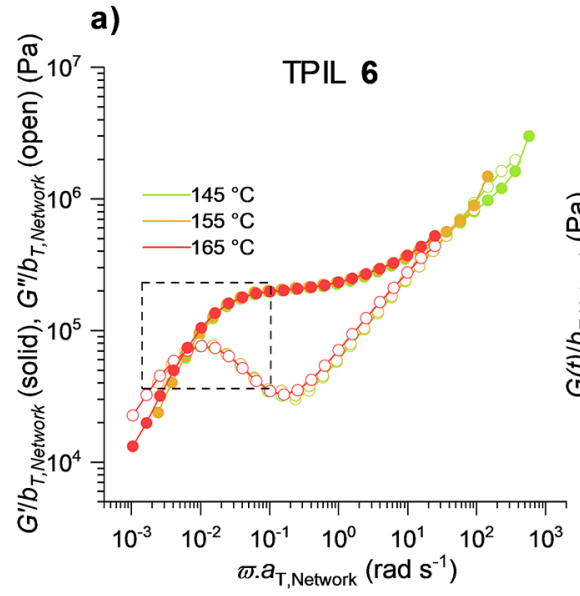

b)

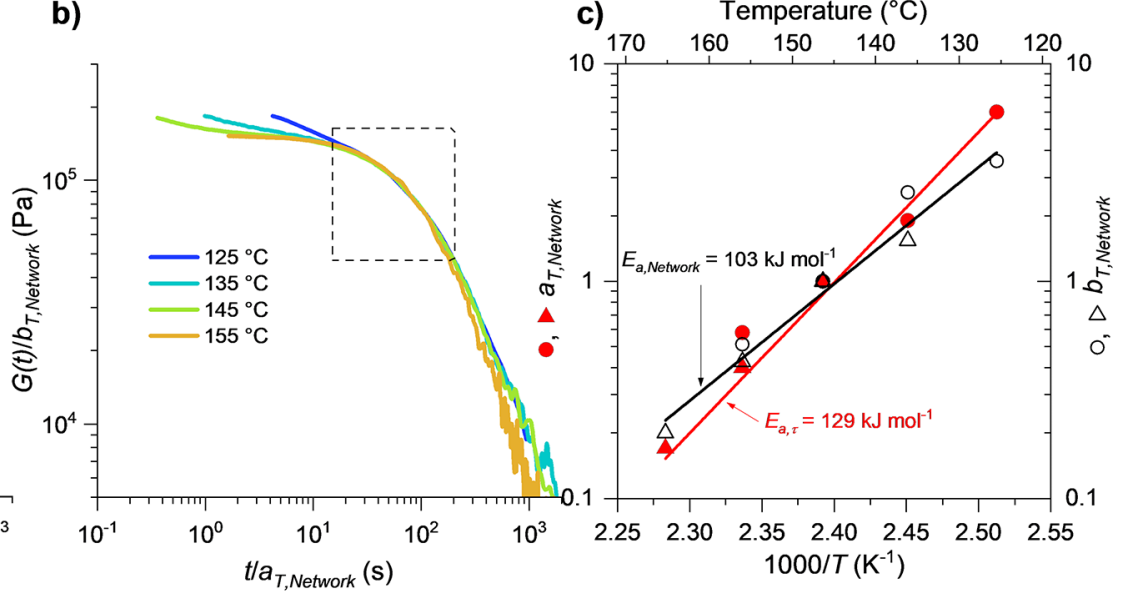

d)

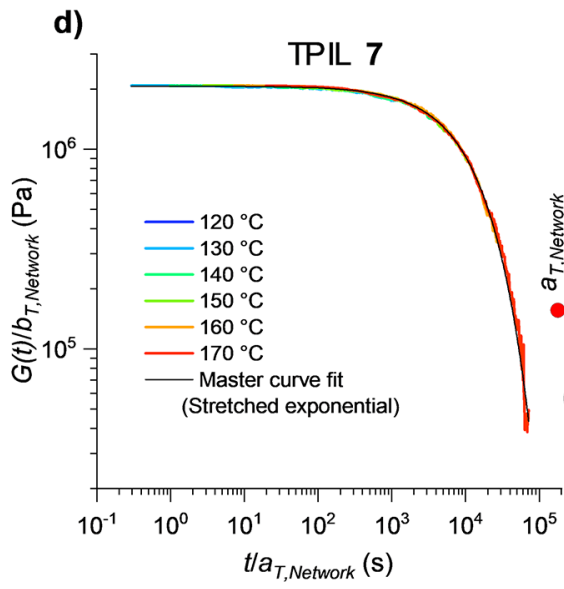

e)

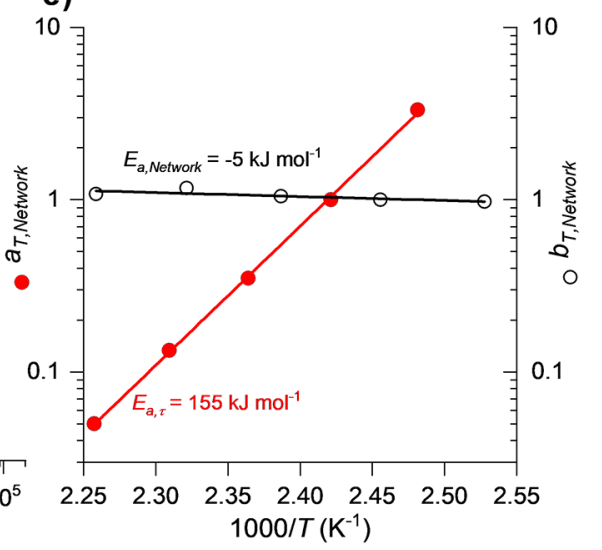

Figure 8. Time-temperature superposition analysis of data presented in Figure 7. Storage and loss moduli shifted at a reference temperature of $145^{\circ} \mathrm{C}$ for 6 (a). Stress relaxation ( $0.25 \%$ strain) shifted at a reference temperature of $145{ }^{\circ} \mathrm{C}$ for $6(\mathrm{~b})$ and $140{ }^{\circ} \mathrm{C}$ for 7 (d). Temperature dependence of the shift factors $\left(a_{T}\right.$ and $b_{T}$ in red and white, respectively) for 6 (c) and 7 (e). Data obtained from SAOS and stress relaxation experiments are represented as triangles and circles, respectively. The solid lines are Arrhenius fits for $a_{T, \text { Network }}\left(\right.$ red) and $b_{T, \text { Network }}$ (black; refer to the text below for a discussion on Arrhenius/Van't Hoff models in this case).

dependence with temperature, which could result from several effects: (1) possible continuation of cross-linking reaction at higher temperatures, which is very difficult to rule out, (2) entropic elasticity $G_{0}=v k T$, and (3) change of material density. The corresponding viscous flow activation energy in this case is almost unchanged in comparison to the kinetic activation energy, $\mathrm{E}_{\mathrm{a}, \eta}=\mathrm{E}_{\mathrm{a}, \tau}+\mathrm{E}_{\mathrm{a}, \text { Network }}=150 \mathrm{~kJ} \mathrm{~mol}^{-1}$, and corresponds to the viscous flow activation energy previously measured with creep experiments on the same material. ${ }^{77}$

The same shifting procedure, only including horizontal shifts $\left(b_{T}=1\right)$, was applied to frequency sweeps at high frequencies (superposition domain delimited by the dashed rectangle in Figure 9a) to capture the dependence of the glass-to-rubber relaxation $H_{\text {Glass }}(\tau, T)$ of the TPIL dynamic network 6 . Figure $9 \mathrm{~b}$ shows a much stronger temperature dependence of $H_{\text {Glass }}(\tau, T)$, which displays as could be expected a super-Arrhenius behavior close to the glass transition well described by a WLF model. Fitting parameters referenced at $T_{0}=145^{\circ} \mathrm{C}$ are $C_{1}=9.6$ and $C_{2}$ $=90.2{ }^{\circ} \mathrm{C}$, which correspond to $C_{1}^{\mathrm{g}}=17.6$ and $C_{2}^{\mathrm{g}}=49.2{ }^{\circ} \mathrm{C}$ referenced at $T_{0}=T_{\mathrm{g}}=104^{\circ} \mathrm{C}$. These last values are in excellent accordance with those of polystyrene (i.e., $C_{1, P S}^{\mathrm{g}}=17.4{ }^{\circ} \mathrm{C}$ and $\left.C_{2, \mathrm{PS}}^{\mathrm{g}}=51.6{ }^{\circ} \mathrm{C}\right) .{ }^{93}$ The strong difference in temperature dependence of the network relaxation and the glass relaxation evidences fundamentally distinct underlying mechanisms than for TPIL dynamic network 6: that is, noncorrelated chemical exchanges at the scale of the cross-links for $H_{\text {Glass }}$ and cooperative motion at the segmental scale for $H_{\text {Network }}$. This difference was already discussed by Leibler and co-workers, ${ }^{22}$ but we provide herein for the first time an experimental evidence using the same set of linear rheological data.

\section{CONCLUSIONS AND PERSPECTIVES}

This Perspective provides a detailed discussion of the rheological properties of the main components of CANs, that is, vitrimers and dissociative networks. The straightforward methodology developed herein shows the extreme importance of considering the temperature evolution of both the relaxation times and the cross-link density of CANs in order to afford a reliable understanding of their overall rheological behaviors. In this regard, we emphasize the fact that although it is rarely done in the literature, ${ }^{2,91,100}$ presenting and discussing nonnormalized stress relaxations, or SAOS for fast exchanges, is of uttermost importance for comprehensive understanding of the rheological behavior of CANs. We refer the reader to the description of rheological experiments in the Supporting Information, where we describe the best practices to minimize compliance issues and to ensure intimate contact between the sample and the geometries. The time-temperature superposition formalism described herein using $a_{T, \text { Network }}$ and $b_{T, \text { Network }}$ shift factors also enables to properly compare at different 

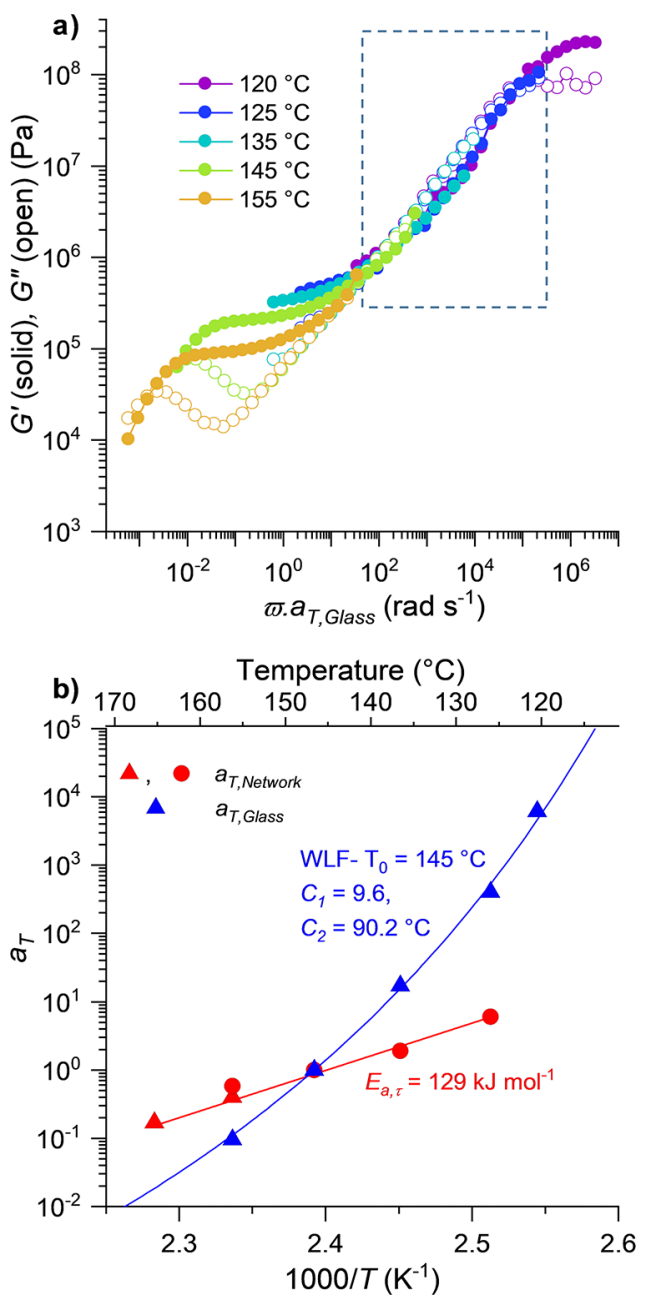

Figure 9. (a) Storage and loss moduli master curves of TPIL dynamic network 6 obtained by shifting data with $a_{T, \text { Glass }}$ factor using as reference a temperature of $145{ }^{\circ} \mathrm{C}$. (b) Comparison of shift factors $a_{T, \text { Glass }}$ (triangles, data obtained from SAOS) fitted by a WLF model and $a_{T, \text { Network }}$ (circles and triangles, data obtained from stress relaxation and SAOS experiments, respectively) fitted by an Arrhenius model.

temperatures complex stress relaxation profiles that cannot be fitted by simple models such as monoexponential or stretched exponential decays and for which, although frequently observed in the literature, determination of relaxation times using $G(\tau)$ / $G_{0}=1 /$ e can be highly misleading.

Using polystyrene-based benzyl-1,2,3-triazolium dynamic networks in which glass transition and rubber-to-liquid transition are relatively close, we were able to characterize both relaxations in the same temperature range and provide clear experimental evidence that even in a short temperature range, the temperature dependences of the glass transition and dynamic network reorganization are distinct and follow WLF and Arrhenius models, respectively.

A special focus is made on 1,2,3-triazolium-based poly(ionic liquid) networks, which constitute singular examples of CANs with extensive tunability of the thermomechanical properties in comparison to other dynamic networks. We have previously shown that trans- $N$-alkylation reactions involving 1,2,3triazolium groups display a large versatility by rational design of the 1,2,3-triazolium substituents, counteranions, and network composition. Although all trans- $\mathrm{N}$-alkylation reactions seem to follow a dissociative mechanism, TPIL dynamic networks incorporating alkyl iodide derivatives involve trans- $N$-alkylation reactions with rates of exchange strongly dependent on temperature $\left(E_{\mathrm{a}, \tau} \sim 140-160 \mathrm{~kJ} \mathrm{~mol}^{-1}\right)$ and a balance of species independent of temperature (regime I CANs) in the $100-170{ }^{\circ} \mathrm{C}$ range, thus displaying rheological behavior almost indiscernible from vitrimers. TPIL dynamic networks incorporating benzyl iodides also display exchange rates with a strong temperature dependence $\left(E_{\mathrm{a}, \tau} \sim 130 \mathrm{~kJ} \mathrm{~mol}^{-1}\right)$ but show in contrast a significant decrease of cross-link density above $140^{\circ} \mathrm{C}$ which is characteristic of partially dissociative networks such as regime II CANs. As a consequence, the temperature dependence of the viscosity in the latter materials is far greater, with a viscous flow activation energy reaching $E_{\mathrm{a}, \eta}=230 \mathrm{~kJ} \mathrm{~mol}^{-1}$. While fully depolymerizable dissociative networks (i.e., regime III CANs) are particularly suited for applications where local or temporary flow is required, such as heat- or UV-irradiationinduced self-healing coatings and composites, ${ }^{101,102}$ or recyclable thermosets, ${ }^{103}$ partially depolymerizable dissociative networks in regime II described herein appear as a good compromise when viscoelasticity is required during the processing steps such as pelletization, filament winding after extrusion, blow molding, ${ }^{104}$ or $3 \mathrm{D}$ printing through the fused filament deposition (FDM) process. ${ }^{105}$ Finally, there are still many additional possibilities to tune the chemical structure and functionality of the building blocks involved in the synthesis of TPIL dynamic networks and to reach a comprehensive understanding of the structure/properties relationships involved in these highly promising members of the CANs family.

\section{ASSOCIATED CONTENT}

\section{Supporting Information}

The Supporting Information is available free of charge at https://pubs.acs.org/doi/10.1021/acs.macromol.9b02204.

Synthetic procedures, ${ }^{1} \mathrm{H}$ NMR, SEC, and TGA of 1-3 and $5,{ }^{1} \mathrm{H}$ and ${ }^{13} \mathrm{C}$ NMR of 4, XPS of 6 for different annealing temperatures, method for the calculation of network composition, methods for rheological characterization, and fits of stress relaxation data (PDF)

\section{AUTHOR INFORMATION}

\section{Corresponding Authors}

Eric Drockenmuller - Univ Lyon, Université Lyon 1, CNRS, Ingénierie des Matériaux Polymères, UMR 5223, F-69003 Lyon, France; 10 orcid.org/0000-0003-0575-279X; Email: eric.drockenmuller@univ-lyon1.fr

Damien Montarnal - Univ Lyon, CPE Lyon, CNRS, Catalyse, Chimie, Polymères et Procédes, UMR 5265, F-69003 Lyon,

France; (o orcid.org/0000-0003-3246-3467; Email: damien.montarnal@univ-lyon1.fr

\section{Authors}

Antoine Jourdain - Univ Lyon, Université Lyon 1, CNRS, Ingénierie des Matériaux Polymères, UMR 5223, F-69003 Lyon, France; ○ orcid.org/0000-0002-6366-3958

Rawnaq Asbai - Univ Lyon, Université Lyon 1, CNRS, Ingénierie des Materiaux Polymères, UMR 5223 and CPE Lyon, CNRS, Catalyse, Chimie, Polymères et Procédes, UMR 5265, F-69003 Lyon, France; (1) orcid.org/0000-0003-4478-2115

Omaima Anaya - Univ Lyon, Université Lyon 1, CNRS, Ingénierie des Matériaux Polymères, UMR 5223, F-69003 Lyon, France; ○ orcid.org/0000-0001-9148-8707 
Mohamed M. Chehimi - Institut de Chimie et des Matériaux Paris-Est, UMR 7182, F-94320 Thiais, France; (1) orcid.org/ 0000-0002-6098-983X

Complete contact information is available at:

https://pubs.acs.org/10.1021/acs.macromol.9b02204

\section{Notes}

The authors declare no competing financial interest.

\section{Biographies}

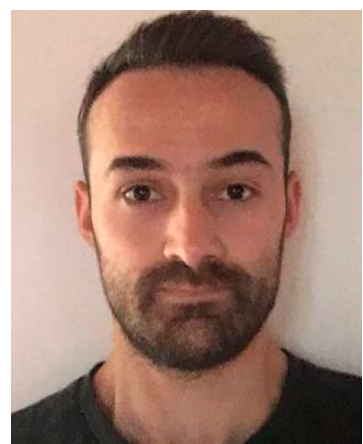

Antoine Jourdain obtained a M.Sc. in polymer chemistry and material sciences at the University of Lyon 1 (France). In 2016, he started a Ph.D. in the group of Prof. E. Drockenmuller working on the design of linear and cross-linked 1,2,3-triazolium-based functional polymer electrolytes with tailored structure and properties.

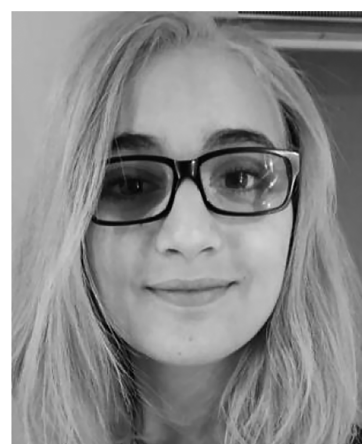

Rawnaq Asbai obtained an Engineering diploma in Materials Science and Engineering from the Lyon National Institute of Science and Technology (INSA-Lyon) in 2018. She then pursued a Ph.D. in the groups of Prof. E. Drockenmuller and Dr. D. Montarnal where she is currently working on the synthesis and characterization of functional and nanostructured covalent adaptable networks.

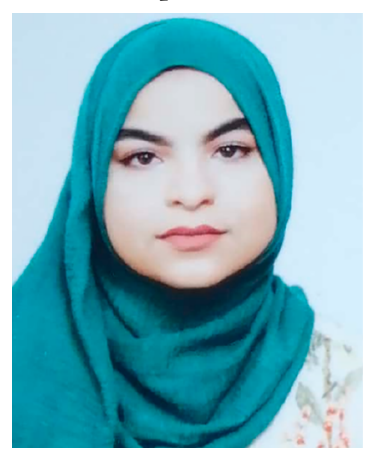

Omaima Anaya obtained a M.Sc. in organic chemistry in 2016 from the Science University of Tunis (Tunisia). Since 2017, she is a Ph.D. student in the groups of Prof. E. Drockenmuller (University of Lyon 1, France) and Prof. H. Ben Romdhane (Science University of Tunis, Tunisia) working on the development of dynamic ion conducting polymer electrolytes.

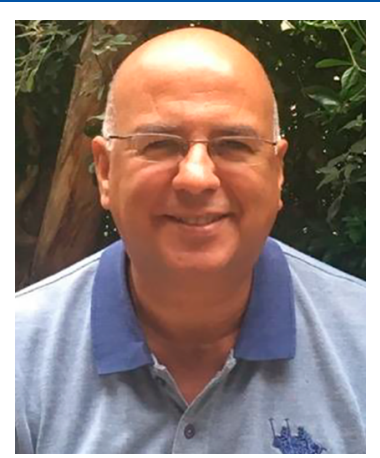

Mohamed M. Chehimi obtained a Ph.D. in physical organic chemistry at the University Paris Diderot in 1988 and is a CNRS research scientist since 1989. His research is focused on the design of reactive and functional polymers and nanocomposite coatings. He is particularly interested in developing aryldiazonium salts as new coupling agents in materials science. The applications encompass adsorbents, sensors and actuators, reactive fillers, antibacterial surfaces, and electronic devices. $\mathrm{He}$ is an expert on X-ray photoelectron spectroscopy analysis of a broad range of materials including polymer composites. Since 2016, he serves as Executive Editor-in-Chief of Chemistry Africa (Springer Nature) and Associate Editor of Surfaces (MDPI).

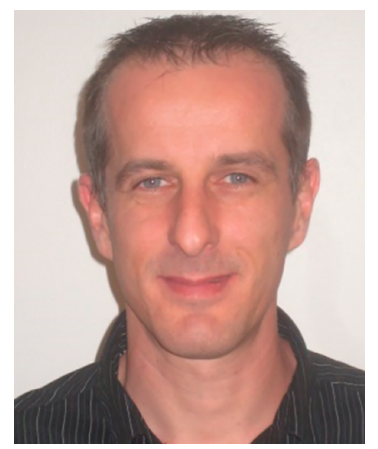

Eric Drockenmuller received his Ph.D. degree in 2002 from the University of Strasbourg (France) after working on nitroxide mediated radical polymerization. In 2002, he joined as postdoctoral fellow the groups of Prof. C. J. Hawker (IBM Almaden Research Center, San Jose, CA) and Prof. T. P. Russell (University of Massachusetts, Amherst, MA) working on the synthesis and functionalization of nanostructured materials. He was appointed assistant professor in 2004 and promoted full professor in 2011 at the University of Lyon 1 (France). His main research interests include the synthesis of tailored functional materials, polymers for energy applications, and ion conducting and dynamic polymer materials.

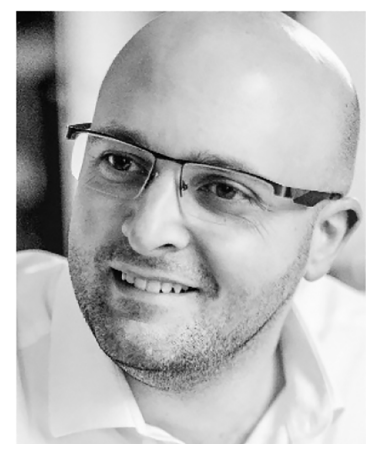

Damien Montarnal obtained his Ph.D. from ESPCI ParisTech, France, in 2011, where he worked on supramolecular self-healing materials and initiated the concept of vitrimers under the supervision of Prof. L. Leibler and Dr. F. Tournilhac. He subsequently moved to UC Santa Barbara as a postdoctoral researcher with Profs C. J. Hawker, E. J. 
Kramer, and G. H. Fredrickson, working on block copolymer selfassembly. He is a CNRS research scientist since 2015, in the laboratory of Chemistry, Catalysis, Polymers and Processes at the University of Lyon 1 (France). His research interests encompass all polymer materials in which reversible chemistry can modulate the structure, dynamics, or physical properties.

\section{ACKNOWLEDGMENTS}

The authors gratefully acknowledge the financial support from the ANR through the MATVIT project (ANR-18-CE06-002601).

\section{REFERENCES}

(1) Scott, T. F.; Schneider, A. D.; Cook, W. D.; Bowman, C. N. Photoinduced Plasticity in Cross-Linked Polymers. Science 2005, 308 (5728), 1615-1617.

(2) Kloxin, C. J.; Scott, T. F.; Adzima, B. J.; Bowman, C. N. Covalent Adaptable Networks (CANs): A Unique Paradigm in Cross-Linked Polymers. Macromolecules 2010, 43 (6), 2643-2653.

(3) Kloxin, C. J.; Bowman, C. N. Covalent Adaptable Networks: smart, reconfigurable and responsive network systems. Chem. Soc. Rev. 2013, 42 (17), 7161-7173.

(4) Zou, W.; Dong, J.; Luo, Y.; Zhao, Q.; Xie, T. Dynamic Covalent Polymer Networks: from Old Chemistry to Modern Day Innovations. Adv. Mater. 2017, 29 (14), 1606100.

(5) Fortman, D. J.; Brutman, J. P.; De Hoe, G. X.; Snyder, R. L.; Dichtel, W. R.; Hillmyer, M. A. Approaches to Sustainable and Continually Recyclable Cross-Linked Polymers. ACS Sustainable Chem. Eng. 2018, 6 (9), 11145-11159.

(6) Zhang, Z. P.; Rong, M. Z.; Zhang, M. Q. Polymers Engineering Based on Reversible Covalent Chemistry: A Promising Innovative Pathway towards New Materials and New Functionalities. Prog. Polym. Sci. 2018, 80, 39-93.

(7) Scheutz, G. M.; Lessard, J. J.; Sims, M. B.; Sumerlin, B. S. Adaptable Crosslinks in Polymeric Materials: Resolving the Intersection of Thermoplastics and Thermosets. J. Am. Chem. Soc. 2019, 141 (41), 16181-16196.

(8) Hempel, E.; Hempel, G.; Hensel, A.; Schick, C.; Donth, E. Characteristic Length of Dynamic Glass Transition near $T_{\mathrm{g}}$ for a Wide Assortment of Glass-Forming Substances. J. Phys. Chem. B 2000, 104 (11), 2460-2466.

(9) Montarnal, D.; Capelot, M.; Tournilhac, F.; Leibler, L. Silica-Like Malleable Materials from Permanent Organic Networks. Science 2011, 334 (6058), 965-967.

(10) Denissen, W.; Winne, J. M.; Du Prez, F. E. Vitrimers: Permanent Organic Networks with Glass-Like Fluidity. Chem. Sci. 2016, 7 (1), 3038.

(11) Winne, J. M.; Leibler, L.; Du Prez, F. E. Dynamic Covalent Chemistry in Polymer Networks: a Mechanistic Perspective. Polym. Chem. 2019, 10 (45), 6091-6108.

(12) Jin, Y.; Lei, Z.; Taynton, P.; Huang, S.; Zhang, W. Malleable and Recyclable Thermosets: The Next Generation of Plastics. Matter 2019, 1 (6), 1456-1493.

(13) Zhang, B.; Digby, Z. A.; Flum, J. A.; Foster, E. M.; Sparks, J. L.; Konkolewicz, D. Self-healing, Malleable and Creep Limiting Materials Using Both Supramolecular and Reversible Covalent Linkages. Polym. Chem. 2015, 6 (42), 7368-7372.

(14) Lyon, G. B.; Baranek, A.; Bowman, C. N. Scaffolded Thermally Remendable Hybrid Polymer Networks. Adv. Funct. Mater. 2016, 26 (9), 1477-1485.

(15) Bowman, C. N.; Kloxin, C. J. Covalent Adaptable Networks: Reversible Bond Structures Incorporated in Polymer Networks. Angew. Chem. 2012, 124 (18), 4346-4348.

(16) Wojtecki, R. J.; Meador, M. A.; Rowan, S. J. Using the Dynamic Bond to Access Macroscopically Responsive Structurally Dynamic Polymers. Nat. Mater. 2011, 10 (1), 14-27.
(17) Denissen, W.; Droesbeke, M.; Nicolaÿ, R.; Leibler, L.; Winne, J. M.; Du Prez, F. E. Chemical Control of the Viscoelastic Properties of Vinylogous Urethane Vitrimers. Nat. Commun. 2017, 8, 14857.

(18) Revell, L. E.; Williamson, B. E. Why Are Some Reactions Slower at Higher Temperatures? J. Chem. Educ. 2013, 90 (8), 1024-1027.

(19) Van Herck, N.; Maes, D.; Unal, K.; Guerre, M.; Winne, J. M.; Du Prez, F. E. Covalent Adaptable Networks with Tunable Exchange Rates Based on Reversible Thiol-Yne Cross-Linking. Angew. Chem., Int. Ed. 2020, 59, 3609.

(20) Taplan, C.; Guerre, M.; Winne, J. M.; Du Prez, F. Fast Processing of Highly Crosslinked, Low-Viscosity Vitrimers. Mater. Horiz. 2020, 7 (1), 104-110.

(21) Capelot, M.; Unterlass, M. M.; Tournilhac, F.; Leibler, L. Catalytic Control of the Vitrimer Glass Transition. ACS Macro Lett. 2012, 1 (7), 789-792.

(22) Lessard, J. J.; Scheutz, G. M.; Sung, S. H.; Lantz, K. A.; Epps, T. H., III; Sumerlin, B. S. Block Copolymer Vitrimers. J. Am. Chem. Soc. 2020, 142 (1), 283-289.

(23) Ricarte, R. G.; Tournilhac, F.; Cloitre, M.; Leibler, L. Linear Viscoelasticity and Flow of Self-Assembled Vitrimers: the Case of a Polyethylene/Dioxaborolane System. Macromolecules 2020, ASAP.

(24) Guerre, M.; Taplan, C.; Nicolä̈, R.; Winne, J. M.; Du Prez, F. E. Fluorinated Vitrimer Elastomers with a dual Temperature Response. J. Am. Chem. Soc. 2018, 140 (41), 13272-13284.

(25) Reddy, V. R.; Dugas, P. Y.; Rawstron, E.; Bourgeat-Lami, E.; Montarnal, D. Improved Malleability of Miniemulsion-Based Vitrimers through in-Situ Generation of Carboxylate Surfactants. Polym. Chem. 2019, 10, 3001.

(26) Brutman, J. P.; Delgado, P. A.; Hillmyer, M. A. Polylactide Vitrimers. ACS Macro Lett. 2014, 3 (7), 607-610.

(27) Altuna, F. I.; Hoppe, C. E.; Williams, R. J. J. Shape Memory Epoxy Vitrimers Based on DGEBA Crosslinked with Dicarboxylic Acids and their Blends with Critic Acid. RSC Adv. 2016, 6 (91), 8864788655.

(28) Demongeot, A.; Groote, R.; Goossens, H.; Hoeks, T.; Tournilhac, F.; Leibler, L. Cross-Linking of Poly(butylene terephthalate) by Reactive Extrusion Using Zn (II) Epoxy-Vitrimer Chemistry. Macromolecules 2017, 50 (16), 6117-6127.

(29) Zhou, Y.; Goossens, J. G. P.; Sijbesma, R. P.; Heuts, J. P. A. Poly(butylene terephthalate)/Glycerol-based Vitrimers via Solid-State Polymerization. Macromolecules 2017, 50 (17), 6742-6751.

(30) Snijkers, F.; Pasquino, R.; Maffezzoli, A. Curing and Viscoelasticity of Vitrimers. Soft Matter 2017, 13 (1), 258-268.

(31) Vaidyula, R. R.; Dugas, P.-Y.; Rawstron, E.; Bourgeat-Lami, E.; Montarnal, D. Improved Malleability of Miniemulsion-based Vitrimers through In situ Generation of Carboxylate Surfactants. Polym. Chem. 2019, 10 (23), 3001-3005.

(32) Zhou, Y.; Goossens, J. G.; van den Bergen, S.; Sijbesma, R. P.; Heuts, J. P. In Situ Network Formation in PBT Vitrimers via Processing-Induced Deprotection Chemistry. Macromol. Rapid Commun. 2018, 39 (19), 1800356.

(33) Zheng, N.; Hou, J.; Xu, Y.; Fang, Z.; Zou, W.; Zhao, Q.; Xie, T. Catalyst-Free Thermoset Polyurethane with Permanent Shape Reconfigurability and Highly Tunable Triple-Shape Memory Performance. ACS Macro Lett. 2017, 6 (4), 326-330.

(34) Zheng, N.; Fang, Z.; Zou, W.; Zhao, Q.; Xie, T. Thermoset Shape-Memory Polyurethane with Intrinsic Plasticity Enabled by Transcarbamoylation. Angew. Chem., Int. Ed. 2016, 55 (38), 1142111425.

(35) Fortman, D. J.; Brutman, J. P.; Cramer, C. J.; Hillmyer, M. A.; Dichtel, W. R. Mechanically Activated, Catalyst-Free Polyhydroxyurethane Vitrimers. J. Am. Chem. Soc. 2015, 137 (44), 14019-14022.

(36) Fortman, D. J.; Brutman, J. P.; Hillmyer, M. A.; Dichtel, W. R. Structural Effects on the Reprocessability and Stress Relaxation of Crosslinked Polyhydroxyurethanes. J. Appl. Polym. Sci. 2017, 134 (45), 44984-44994.

(37) Chen, X.; Li, L.; Wei, T.; Venerus, D. C.; Torkelson, M. J. Reprocessable Polyhydroxyurethane Network Composites: Effect of 
Filler Surface Functionality on Cross-link Density Recovery and Stress Relaxtion. ACS Appl. Mater. Interfaces 2019, 11 (2), 2398-2407.

(38) Snyder, R. L.; Fortman, D. J.; De Hoe, G. X.; Hillmyer, M. A.; Dichtel, W. R. Reprocessable Acid-Degradable Polycarbonate Vitrimers. Macromolecules 2018, 51 (2), 389-397.

(39) Denissen, W.; Rivero, G.; Nicolaÿ, R.; Leibler, L.; Winne, J. M.; $\mathrm{Du}$ Prez, F. E. Vinylogous Urethane Vitrimers. Adv. Funct. Mater. 2015, 25 (16), 2451-2457.

(40) Zhang, H.; Wang, D.; Liu, W.; Li, P.; Liu, J.; Liu, C.; Zhang, J.; Zhao, N.; Xu, J. Recyclable Polybutadiene Elastomer Based On Dynamic Imine Bond. J. Polym. Sci., Part A: Polym. Chem. 2017, 55 (12), 2011-2018.

(41) Zheng, H.; Liu, Q.; Lei, X.; Chen, Y.; Zhang, B.; Zhang, Q. A Conjugation Polyimine Vitrimer: Fabrication and Performance. $J$. Polym. Sci., Part A: Polym. Chem. 2018, 56 (22), 2531-2538.

(42) Wang, S.; Ma, S.; Li, Q.; Yuan, W.; Wang, B.; Zhu, J. Robust, FireSafe, Monomer-Recovery, Highly Malleable Thermosets from Renewable Bioresources. Macromolecules 2018, 51 (20), 8001-8012.

(43) Hendriks, B.; Waelkens, J.; Winne, J. M.; Du Prez, F. E. Poly(thioether) Vitrimers via Transalkylation of Trialkylsulfonium Salts. ACS Macro Lett. 2017, 6 (9), 930-934.

(44) Tang, Z.; Liu, Y.; Huang, Q.; Zhao, J.; Guo, B.; Zhang, L. A Real Recycling Loop of Sulfur-cured Rubber through Transalkylation Exchange of C-S Bonds. Green Chem. 2018, 20 (24), 5454-5458.

(45) Nishimura, Y.; Chung, J.; Muradyan, H.; Guan, Z. Silyl Ether as a Robust and Thermally Stable Dynamic Covalent Motif for Malleable Polymer Design. J. Am. Chem. Soc. 2017, 139 (42), 14881-14884.

(46) Wu, X.; Yang, X.; Yu, R.; Zhao, X.-J.; Zhang, Y.; Huang, W. A Facile Access to Stiff Epoxy Vitrimers with Excellent Mechanical Properties via Siloxane Equilibration. J. Mater. Chem. A 2018, 6 (22), 10184-10188.

(47) Wu, S.; Yang, Z.; Fang, S.; Tang, Z.; Liu, F.; Guo, B. Malleable Organic/Inorganic Thermosetting Hybrids Enabled by Exchangeable Eilyl Ether Interfaces. J. Mater. Chem. A 2019, 7 (4), 1459-1467.

(48) He, C.; Shi, S.; Wang, D.; Helms, B. A.; Russell, T. P. Poly(oxime-ester) Vitrimers with Catalyst-Free Bond Exchange. J. Am. Chem. Soc. 2019, 141 (35), 13753-13757.

(49) Ishibashi, J. S. A.; Kalow, J. A. Vitrimeric Silicone Elastomers Enabled by Dynamic Meldrum's Acid-Derived Cross-Links. ACS Macro Lett. 2018, 7 (4), 482-486.

(50) Chao, A.; Zhang, D. Investigation of Secondary Amine-Derived Aminal Bond Exchange toward the Development of Covalent Adaptable Networks. Macromolecules 2019, 52 (2), 495-503.

(51) Christensen, P. R.; Scheuermann, A. M.; Loeffler, K. E.; Helms, B. A. Closed-loop Recycling of Plastics Enabled by Dynamic Covalent Diketoenamine Bonds. Nat. Chem. 2019, 11 (5), 442-448.

(52) Ruiz de Luzuriaga, A.; Martin, R.; Markaide, N.; Rekondo, A.; Cabañero, G.; Rodriguez, J.; Odriozola, I. Epoxy Resin with Exchangeable Disulfide Crosslinks to Obtain Reprocessable, Repairable and Recyclable Fiber-Reinforced Thermoset Composites. Mater. Horiz. 2016, 3 (3), 241-247.

(53) Ma, Z.; Wang, Y.; Zhu, J.; Yu, J.; Hu, Z. Bio-Based Epoxy Vitrimers: Reprocessibility, Controllable Shape Memory, and Degradability. J. Polym. Sci., Part A: Polym. Chem. 2017, 55 (10), 1790-1799.

(54) Lu, Y.-X.; Guan, Z. Olefin Metathesis for Effective Polymer Healing via Dynamic Exchange of Strong Carbon-Carbon Double Bonds. J. Am. Chem. Soc. 2012, 134 (34), 14226-14231.

(55) Röttger, M.; Domenech, T.; van der Weegen, R.; Breuillac, A.; Nicolaÿ, R.; Leibler, L. High-Performance Vitrimers from Commodity Thermoplastics through Dioxaborolane Metathesis. Science 2017, 356 (6333), 62-65.

(56) Chen, Y.; Tang, Z.; Zhang, X.; Liu, Y.; Wu, S.; Guo, B. Covalently Cross-Linked Elastomers with Self-Healing and Malleable Abilities Enabled by Boronic Ester Bonds. ACS Appl. Mater. Interfaces 2018, 10 (28), 24224-24231.

(57) Caffy, F.; Nicolaÿ, R. Transformation of Polyethylene into a Vitrimer by Nitroxide Radical Coupling of a Bis-Dioxaborolane. Polym. Chem. 2019, 10 (23), 3107-3115.
(58) Meng, F.; Saed, M. O.; Terentjev, E. M. Elasticity and Relaxation in Full and Partial Vitrimer Networks. Macromolecules 2019, 52 (17), 7423-7429.

(59) Brunet, J.; Collas, F.; Humbert, M.; Perrin, L.; Brunel, F.; Lacôte, E.; Montarnal, D.; Raynaud, J. High Glass-Transition Temperature Polymer Networks Harnessing the Dynamic Ring Opening of Pinacol Boronates. Angew. Chem., Int. Ed. 2019, 58 (35), 12216-12222.

(60) Pei, Z.; Yang, Y.; Chen, Q.; Wei, Y.; Ji, Y. Regional Shape Control of Strategically Assembled Multishape Memory Vitrimers. Adv. Mater. 2016, 28 (1), 156-160.

(61) Capelot, M.; Montarnal, D.; Tournilhac, F.; Leibler, L. MetalCatalyzed Transesterification for Healing and Assembling of Thermosets. J. Am. Chem. Soc. 2012, 134 (18), 7664-7667.

(62) Zheng, N.; Fang, Z.; Zou, W.; Zhao, Q.; Xie, T. Thermoset Shape-Memory Polyurethane with Intrinsic Plasticity Enabled by Transcarbamoylation. Angew. Chem., Int. Ed. 2016, 55 (38), 1142111425.

(63) Chen, X.; Dam, M. A.; Kanji, O.; Mal, A.; Shen, H.; Nutt, S. R.; Sheran, K.; Wudl, F. A Thermally Re-mendable Cross-Linked Polymeric Material. Science 2002, 295 (5560), 1698-1702.

(64) Houck, H. A.; De Bruycker, K.; Billiet, S.; Dhanis, B.; Goossens, H.; Catak, S.; Van Speybroeck, V.; Winne, J. M.; Du Prez, F. E. Design of a Thermally Controlled Sequence of Triazolinedione-Based Click and Transclick Reactions. Chem. Sci. 2017, 8 (4), 3098-3108.

(65) Lendlein, A.; Jiang, H.; Jünger, O.; Langer, R. Light-Induced Shape-Memory Polymers. Nature 2005, 434 (7035), 879-882.

(66) Zheng, Y.; Micic, M.; Mello, S. V.; Mabrouki, M.; Andreopoulos, F. M.; Konka, V.; Pham, S. M.; Leblanc, R. M. PEG-Based Hydrogel Synthesis via the Photodimerization of Anthracene Groups. Macromolecules 2002, 35 (13), 5228-5234.

(67) Defize, T.; Thomassin, J.-M.; Ottevaere, H.; Malherbe, C.; Eppe, G.; Jellali, R.; Alexandre, M.; Jérôme, C.; Riva, R. Photo-Cross-Linkable Coumarin-Based Poly $(\varepsilon$-caprolactone $)$ for Light-Controlled Design and Reconfiguration of Shape-Memory Polymer Networks. Macromolecules 2019, 52 (2), 444-456.

(68) Ferry, J. D. Viscoelastic Properties of Polymers, 3rd ed.; Wiley: New York, 1980; pp 273-313.

(69) Adzima, B. J.; Aguirre, H. A.; Kloxin, C. J.; Scott, T. F.; Bowman, C. N. Rheological and Chemical Analysis of Reverse Gelation in a Covalently Cross-Linked Diels-Alder Polymer Network. Macromolecules 2008, 41 (23), 9112-9117.

(70) Kuang, X.; Liu, G.; Dong, X.; Wang, D. Correlation between Stress Relaxation Dynamics and Thermochemistry for Covalent Adaptive Networks Polymers. Mater. Chem. Front. 2017, 1 (1), 111118.

(71) Semenov, A. N.; Rubinstein, M. Thermoreversible Gelation in Solutions of Associative Polymers. 1. Statics. Macromolecules 1998, 31 (4), 1373-1385.

(72) Obadia, M. M.; Drockenmuller, E. Poly(1,2,3-triazoliums): a New Class of Functional Polymer Electrolytes. Chem. Commun. 2016, 52 (12), 2433-2450.

(73) Obadia, M. M.; Mudraboyina, B. P.; Allaoua, I.; Haddane, A.; Montarnal, D.; Serghei, A.; Drockenmuller, E. Accelerated Solvent- and Catalyst-Free Synthesis of 1,2,3-Triazolium-Based Poly(Ionic Liquid)s. Macromol. Rapid Commun. 2014, 35 (8), 794-800.

(74) Obadia, M. M.; Crepet, A.; Serghei, A.; Montarnal, D.; Drockenmuller, E. Expanding the Structural Variety of Poly(1,2,3triazolium)s Obtained by Simultaneous 1,3-dipolar Huisgen Polyaddition and N-alkylation. Polymer 2015, 79, 309-315.

(75) Obadia, M. M.; Mudraboyina, B. P.; Serghei, A.; Montarnal, D.; Drockenmuller, E. Reprocessing and Recycling of Highly Cross-Linked Ion-Conducting Networks through Transalkylation Exchanges of C-N Bonds. J. Am. Chem. Soc. 2015, 137 (44), 6078-6083.

(76) Zhou, X.; Obadia, M. M.; Venna, S. R.; Roth, E. A.; Serghei, A.; Luebke, D. R.; Myers, C.; Chang, Z.; Enick, R.; Drockenmuller, E.; Nulwala, H. B. Highly Cross-Linked Polyether-Based 1,2,3-Triazolium Ion Conducting Membranes with Enhanced Gas Separation Properties. Eur. Polym. J. 2016, 84, 65-76. 
(77) Obadia, M. M.; Jourdain, A.; Cassagnau, P.; Montarnal, D.; Drockenmuller, E. Tuning the Viscosity Profile of Ionic Vitrimers Incorporating 1,2,3-Triazolium Cross-Links. Adv. Funct. Mater. 2017, $27(45), 1703258$

(78) Tang, J.; Wan, L.; Zhou, Y.; Pan, H.; Huang, F. Strong and Efficient Self-Healing Adhesives Based on Dynamic Quaternization Cross-Links. J. Mater. Chem. A 2017, 5 (40), 21169-21177.

(79) Lopez, G.; Granado, L.; Coquil, G.; Lárez-Sosa, A.; Louvain, N.; Améduri, B. Perfluoropolyether (PFPE)-Based Vitrimers with Ionic Conductivity. Macromolecules 2019, 52 (5), 2148-2155.

(80) Chakma, P.; Digby, Z. A.; Shulman, M. P.; Kuhn, L. R.; Morley, C. N.; Sparks, J. L.; Konkolewicz, D. Anilinium Salts in Polymer Networks for Materials with Mechanical Stability and Mild Thermally Induced Dynamic Properties. ACS Macro Lett. 2019, 8 (2), 95-100.

(81) Chakma, P.; Morley, C. N.; Sparks, J. L.; Konkolewicz, D. Exploring How Vitrimer-like Properties Can Be Achieved from Dissociative Exchange in Anilinium Salts. Macromolecules 2020, 53, 1233.

(82) Huang, J.; Zhang, L.; Tang, Z.; Wu, S.; Guo, B. Reprocessable and Robust Crosslinked Elastomers via Interfacial C-N Transalkylation of Pyridinium. Compos. Sci. Technol. 2018, 168, 320-326.

(83) Zhang, L.; Rowan, S. J. Effect of Sterics and Degree of CrossLinking on the Mechanical Properties of Dynamic Poly(alkylureaurethane) Networks. Macromolecules 2017, 50 (13), 5051-5060.

(84) Chen, L.; Zhang, L.; Griffin, P. J.; Rowan, S. J. Impact of Dynamic Bond Concentration on the Viscoelastic and Mechanical Properties of Dynamic Poly(alkylurea-courethane) Networks. Macromol. Chem. Phys. 2020, 221 (1), 1900440.

(85) Brutman, J. P.; Fortman, D. J.; De Hoe, G. X.; Dichtel, W. R.; Hillmyer, M. A. Mechanistic Study of stress Relaxation in UrethaneContaining Polymer Networks. J. Phys. Chem. B 2019, 123 (6), 14321441.

(86) Chen, X.; Li, L.; Jin, K.; Torkelson, J. M. Reprocessable Polyhydroxyurethane Networks Exhibiting Full Property Recovery and Concurrent Associative and Dissociative Dynamic Chemistry via Transcarbamoylation and Reversible Cyclic Carbonate Aminolysis. Polym. Chem. 2017, 8 (41), 6349-6355.

(87) Nevejans, S.; Ballard, N.; Miranda, J. I.; Reck, B.; Asua, J. M. The Underlying Mechanisms for Self-healing of Poly(disulfide)s. Phys. Chem. Chem. Phys. 2016, 18 (39), 27577-27583.

(88) Tonnar, J.; Lacroix-Desmazes, P. Controlled Radical Polymerization of Styrene by Iodine Transfer Polymerization (ITP) in ab Initio Emulsion Polymerization. Polymer 2016, 106, 267-274.

(89) Claudy, P.; Letoffe, J.; Camberlain, Y.; Pascault, J. Glass Transition of Polystyrene Versus Molecular Weight. Polym. Bull. 1983, 9 (4-5), 208-215.

(90) Robaugh, D.; Tsang, W. Thermal Decomposition of Phenyl Iodide and o-Iodotoluene. J. Phys. Chem. 1986, 90 (21), 5363-5367.

(91) Breuillac, A.; Kassalias, A.; Nicolaÿ, R. Polybutadiene Vitrimers Based on Dioxaborolane Chemistry and Dual Networks with Static and Dynamic Cross-links. Macromolecules 2019, 52 (18), 7102-7113.

(92) Taplan, C.; Guerre, M.; Winne, J. M.; Du Prez, F. Fast Processing of Highly Crosslinked, Low-Viscosity Vitrimers. Mater. Horiz. 2020, 7, 104.

(93) Williams, M. L.; Landel, R. F.; Ferry, J. D. The Temperature Dependence of Relaxation Mechanisms in Amorphous Polymers and Other Glass-forming Liquids. J. Am. Chem. Soc. 1955, 77 (14), 37013707.

(94) Rosedale, J. H.; Bates, F. S. Rheology of Ordered and Disordered Symmetric Poly(ethylenepropylene)-Poly(ethylethylene) Diblock Copolymers. Macromolecules 1990, 23 (8), 2329.

(95) Rubinstein, M.; Obukhov, S. Power-Law-like Stress Relaxation of Block Copolymers: Disentanglement Regimes. Macromolecules 1993, 26 (7), 1740-1750.

(96) Ricarte, R. G.; Tournilhac, F.; Cloitre, M.; Leibler, L. Linear Viscoelasticity and Flow of Self-Assembled Vitrimers: the Case of a Polyethylene/Dioxaborolane System. Macromolecules 2019, 52 (2), 432-443.
(97) Weiss, R.; Zhao, H. Rheological Behavior of Oligomeric Ionomers. J. Rheol. 2009, 53 (1), 191-213.

(98) Rubinstein, M.; Colby, R. H. Polymer Physics; Oxford University Press: Oxford, 2003.

(99) Dealy, J.; Plazek, D. Time-temperature superposition-a users guide. Rheol. Bull. 2009, 78, 16-31.

(100) Altuna, F. I.; Casado, U.; dell'Erba, I. E.; Luna, L.; Hoppe, C. E.; Williams, R. J. J. Epoxy Vitrimers Incorporating Physical Crosslinks Produced by Self-Association of Alkyl Chains. Polym. Chem. 2020, 11, 1337.

(101) Diaz, M.; Brancart, J.; Van Assche, G.; Van Mele, B. RoomTemperature Versus Heating-Mediated Healing of a Diels-Alder Crosslinked Polymer Network. Polymer 2018, 153, 453-463.

(102) Brancart, J.; Verhelle, R.; Mangialetto, J.; Van Assche, G. Coupling the Microscopic Healing Behaviour of Coatings to the Thermoreversible Diels-Alder Network Formation. Coatings 2019, 9 (1), 13.

(103) McBride, M. K.; Worrell, B. T.; Brown, T.; Cox, L. M.; Sowan, N.; Wang, C.; Podgorski, M.; Martinez, A. M.; Bowman, C. N. Enabling Applications of Covalent Adaptable Networks. Annu. Rev. Chem. Biomol. Eng. 2019, 10 (1), 175-198.

(104) Jin, K.; Kim, S.; Xu, J.; Bates, F. S.; Ellison, C. J. Melt-Blown Cross-Linked Fibers from Thermally Reversible Diels-Alder Polymer Networks. ACS Macro Lett. 2018, 7 (11), 1339-1345.

(105) Yang, K.; Grant, J. C.; Lamey, P.; Joshi-Imre, A.; Lund, B. R.; Smaldone, R. A.; Voit, W. Diels-Alder Reversible Thermoset 3D Printing: Isotropic Thermoset Polymers via Fused Filament Fabrication. Adv. Funct. Mater. 2017, 27 (24), 1700318. 